\title{
Inactivation, Clearance, and Functional Effects of Lung-Instilled Short and Long Silver Nanowires in Rats
}

Kian Fan Chung, ${ }^{* \dagger}{ }^{\dagger}$ Joanna Seiffert, ${ }^{\dagger}$ Shu Chen, ${ }^{\ddagger}$ Ioannis G. Theodorou, ${ }^{\ddagger}$ Angela Erin Goode, ${ }^{\ddagger}$ Bey Fen Leo, ${ }^{\ddagger}, \S^{\circ}$ Catriona M. McGilvery, ${ }^{\ddagger}$ Farhana Hussain, ${ }^{\dagger}$ Coen Wiegman, ${ }^{\dagger}$ Christos Rossios, ${ }^{\dagger}$ Jie Zhu, ${ }^{\dagger}$ Jicheng Gong, $\|$ Farid Tariq, ${ }^{\perp}$ Vladimir Yufit, ${ }^{\perp}$ Alexander J. Monteith, ${ }^{\#}$ Teruo Hashimoto, ${ }^{\bigcirc}$ Jeremy N. Skepper, ${ }^{\nabla}$ Mary P. Ryan, ${ }^{;}$Junfeng Zhang, ${ }^{\|}$Teresa D. Tetley, ${ }^{\dagger}$ and Alexandra E. Porter ${ }^{\ddagger}$

${ }^{\dagger}$ Airways Disease, National Heart and Lung Institute, "Department of Materials and London Centre for Nanotechnology, and

${ }^{\perp}$ Department of Earth Science, Imperial College, London SW7 2AZ, United Kingdom

${ }^{\S}$ Nanotechnology and Catalysis Research Centre (NANOCAT), University of Malaya, Kuala Lumpur 50603, Malaysia

"Nicholas School of Environment and Duke Global Health Institute, Duke University, Durham, North Carolina 27708, United States

\#Department of Biological Sciences, Oxford Brookes University, Oxford OX3 OBP, United Kingdom

${ }^{\circ}$ The School of Materials, The University of Manchester, Oxford Road, Manchester M13 9PL, United Kingdom

${ }^{\nabla}$ Cambridge Advanced Imaging Centre, Department of Anatomy, University of Cambridge, Tennis Court Road, Cambridge CB2 3DY United Kingdom

(5) Supporting Information

ABSTRACT: There is a potential for silver nanowires (AgNWs) to be inhaled, but there is little information on their health effects and their chemical transformation inside the lungs in vivo. We studied the effects of short (S-AgNWs; $1.5 \mu \mathrm{m}$ ) and long (L-AgNWs; $10 \mu \mathrm{m})$ nanowires instilled into the lungs of Sprague-Dawley rats. S- and L-AgNWs were phagocytosed and degraded by macrophages; there was no frustrated phagocytosis. Interestingly, both AgNWs were internalized in alveolar epithelial cells, with precipitation of $\mathrm{Ag}_{2} \mathrm{~S}$ on their surface as secondary $\mathrm{Ag}_{2} \mathrm{~S}$ nanoparticles. Quantitative serial block face three-dimensional scanning electron microscopy showed a small, but significant, reduction of NW lengths inside alveolar epithelial cells. AgNWs were also present in the lung subpleural space where L-AgNWs exposure resulted in more Ag+ve macrophages situated within the pleura and subpleural alveoli,
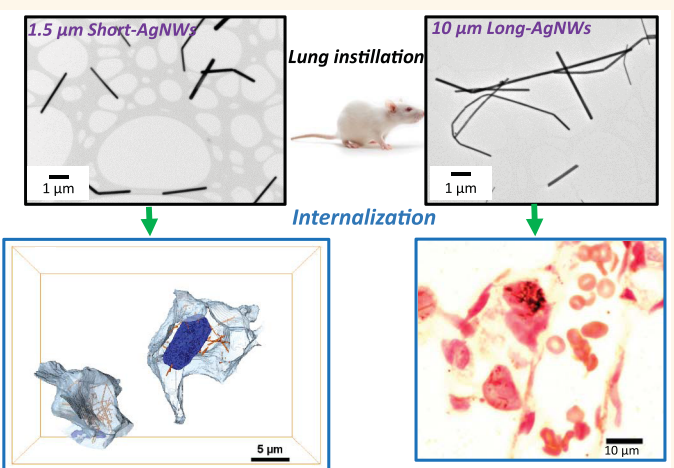
compared with the S-AgNWs exposure. For both AgNWs, there was lung inflammation at day 1 , disappearing by day 21 , but in bronchoalveolar lavage fluid (BALF), L-AgNWs caused a delayed neutrophilic and macrophagic inflammation, while S-AgNWs caused only acute transient neutrophilia. Surfactant protein D (SP-D) levels in BALF increased after S- and L-AgNWs exposure at day 7. L-AgNWs induced MIP-1 $\alpha$ and S-AgNWs induced IL-18 at day 1. Large airway bronchial responsiveness to acetylcholine increased following L-AgNWs, but not S-AgNWs, exposure. The attenuated response to AgNW instillation may be due to silver inactivation after precipitation of $\mathrm{Ag}_{2} \mathrm{~S}$ with limited dissolution. Our findings have important consequences for the safety of silver-based technologies to human health.

KEYWORDS: silver nanowires, alveolar epithelial cells, macrophages, silver sulfidation, surfactant protein D,

bronchial hyperresponsiveness

S

ilver nanomaterials are increasingly used in industrial and domestic products ranging from odor-resistant socks, personal care products, respiratory devices, food storage boxes, computers, and cleaning sprays. Silver nanowires (AgNWs) with a high aspect ratio are also becoming important in the field of optoelectronics, where they are used in the production of transparent, conductive thin-film electrodes for touchscreens, smart phones, and computers. ${ }^{1,2}$ Potentially, there is a high risk of aerosolization associated with industrial processes that manufacture nanolayer films, involving the deposition of tiny droplets

Received: October 30, 2016

Accepted: February 21, 2017

Published: February 21, 2017 

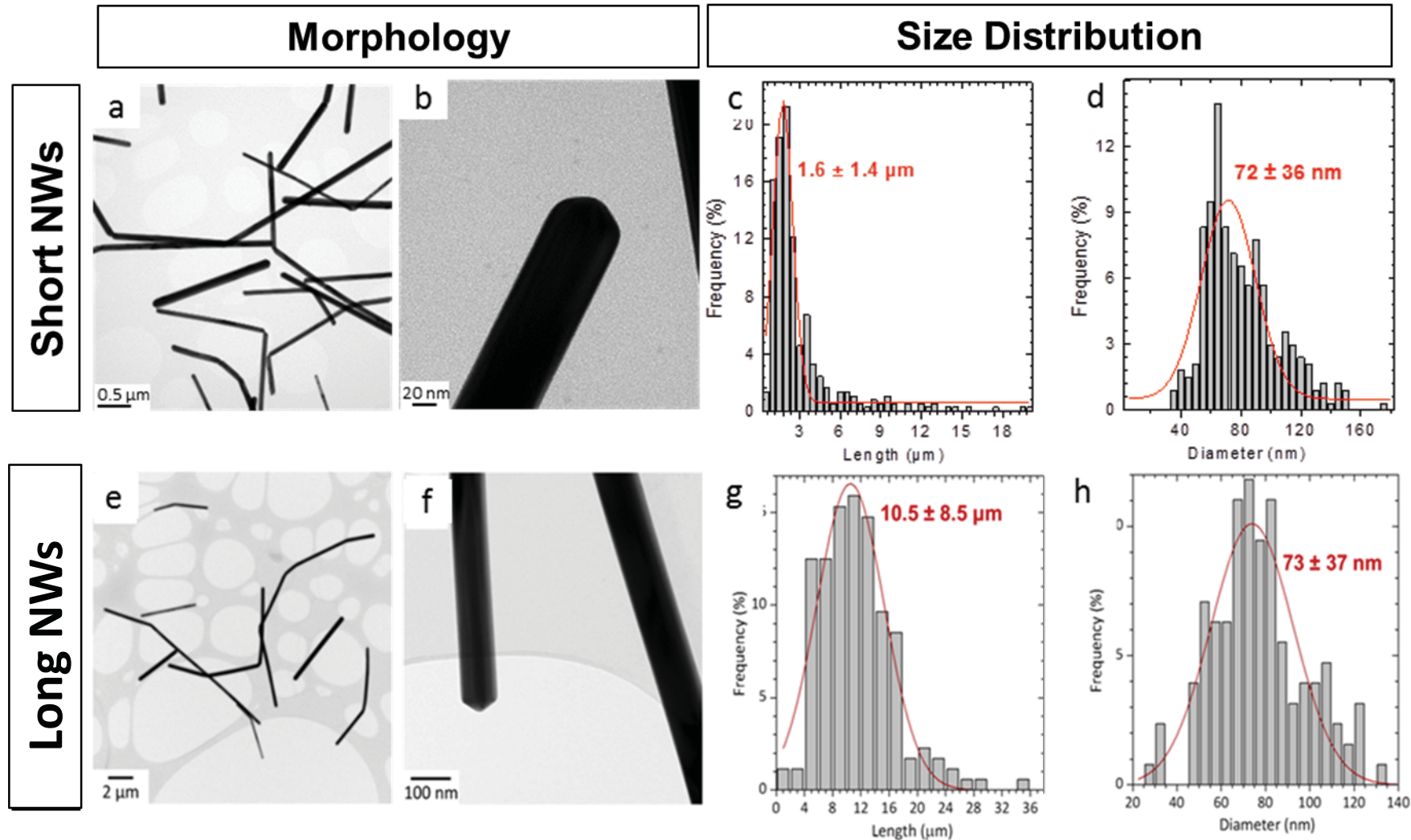

Figure 1. Characterization of as-synthesized AgNWs. BF-TEM images of S-NWs (a and b), l-NWs (e and f), and their length (c and g) and diameter $(\mathrm{d}$ and $\mathrm{h}$ ) distributions. The curves in $(\mathrm{c}, \mathrm{d}, \mathrm{g}$, and $\mathrm{h}$ ) represent the Gaussian fit to the data.

of suspensions of AgNWs onto surfaces, ${ }^{3}$ and therefore of increased risk of inhalation by such workers. ${ }^{4}$

Inhalation and instillation of silver nanoparticles (AgNPs) mainly as nanospheres have been reported to induce dosedependent inflammation ${ }^{5,6}$ and alterations in lung function, including bronchial hyperresponsiveness. ${ }^{7-9}$ A very limited number of studies have investigated the toxicity of AgNWs in vivo. AgNWs $\geq 5 \mu \mathrm{m}$ in length instilled directly into the pleural cavity induced pulmonary inflammation, and those $>10 \mu \mathrm{m}$ induced "frustrated phagocytosis". ${ }^{10,11}$ Intratracheally instilled AgNWs produced similar length-dependent frustrated phagocytic responses, including macrophage clumping and ineffective clearance from the lungs, together with a neutrophilic and eosinophilic response induced by the long $(20 \mu \mathrm{m})$ and short $(2 \mu \mathrm{m})$ AgNWs. $^{12}$ With these very limited available studies, little is known about how the shape or aspect ratio of AgNWs can affect uptake, processing, and biopersistence by lung cells, or if the release of $\mathrm{Ag}^{+}$ion in vivo alters signaling pathways or leads to alterations in pulmonary function. There is growing evidence that AgNPs and AgNWs can enter epithelial cells, interstitial sites, airway smooth muscle cells, the vascular endothelium, and the pleural membrane. ${ }^{10-12}$ Another aspect is that interaction of nanoparticles with lung lining fluid containing pulmonary surfactant is known to influence uptake of nanowires by alveolar epithelial cells ${ }^{13}$ and also the aggregation of nanowires for clearance by alveolar macrophages. ${ }^{14}$ Moreover, the effect of AgNWs on the trafficking or production of surfactant proteins such as surfactant protein D (SP-D) is unclear.

We hypothesized that AgNWs could undergo oxidative dissolution as silver ions $\left(\mathrm{Ag}^{+}\right)$, and so the chemical nature of the AgNWs in the local environment would change with time. Therefore, both size-aspect ratio and $\mathrm{Ag}^{+}$ion release and transformation to $\mathrm{Ag}$ salts could be critical in determining the biopersistence and cytotoxicity of AgNWs. This process of intracellular transformation has been demonstrated in our previous work for a single AgNW length in in vitro cell cultures, ${ }^{15}$ and a recent study demonstrated the intracellular transformation of spherical AgNPs into nano- $\mathrm{Ag}_{2} \mathrm{~S}$ on the surface. ${ }^{16}$ There is no evidence so far that this process occurs in vivo. There is also no understanding of how this high aspect ratio nanomaterial is distributed, internalized, and transformed inside lung cells in vivo, how this process is influenced by AgNW length, and whether these processes could be correlated to inflammatory responses, pulmonary function and responsiveness, and the persistence of silver in the lungs. Therefore, in this study, we use backscattered and serial block face scanning electron microscopy (SEM) to map and generate three-dimensional (3D) volume reconstruction of the morphology of the AgNWs inside the alveoli. Transmission electron microscopy (TEM) combined with energy dispersive-X-ray spectroscopy (EDX) were used to characterize the size, bulk, and surface chemistry and any chemical and morphological transformations of instilled short and long AgNWs (1 and $10 \mu \mathrm{m}$ length) in vivo. ${ }^{17}$ This information was correlated to length-dependent biological responses of AgNWs in the lung by measuring inflammation, chemokine and cytokine profiles, alterations in surfactant composition, and pulmonary function.

\section{RESULTS/DISCUSSION}

Characteristics of Long and Short Silver Nanowires. The polyvinyl pyrrolidone (PVP)-capped short silver nanowires (S-AgNWs) have been characterized previously. ${ }^{15,17}$ S-AgNWs (Figure 1a,b) had an average length of $1.6 \pm 1.4 \mu \mathrm{m}$ (Figure 1c) 
Table 1. Physicochemical Characteristics of Silver Nanowires

\begin{tabular}{|c|c|c|c|c|c|c|c|}
\hline $\begin{array}{c}\text { silver } \\
\text { nanomaterial }\end{array}$ & $\begin{array}{l}\text { capping } \\
\text { agent }\end{array}$ & diameter & length & $\begin{array}{l}\text { mean } \\
\text { aspect } \\
\text { ratio }\end{array}$ & $\begin{array}{l}\text { hydrodynamic } \\
\text { size }\end{array}$ & surface charge & $\begin{array}{c}\text { solubility (\% release as free } \mathrm{Ag}^{+} \\
\text {ions) }\end{array}$ \\
\hline S-AgNW & $\begin{array}{l}\mathrm{PVP} \\
M_{\mathrm{W}} \approx \\
360 \mathrm{k}\end{array}$ & $72 \mathrm{~nm}(36-108 \mathrm{~nm})$ & $1.5 \mu \mathrm{m}(0.1-3.1 \mu \mathrm{m})$ & 20 & $\begin{array}{l}807 \pm 66 \mathrm{~nm} \\
\quad(\mathrm{DI} \text { water })\end{array}$ & $-14.8 \pm 0.1 \mathrm{mV}$ & $\begin{array}{l}\text { pH } 724 \text { h: } 0.3 \%, 14 \text { days: } \\
0.04 \% \text {; pH } 524 \text { h: } 1.5 \%, 14 \\
\text { days: } 1.8 \%\end{array}$ \\
\hline L-AgNW & $\begin{array}{l}\text { PVP } \\
M_{\mathrm{W}} \approx \\
360 \mathrm{k}\end{array}$ & $73 \mathrm{~nm}(42-128 \mathrm{~nm})$ & $10 \mu \mathrm{m}(0.2-35 \mu \mathrm{m})$ & 137 & $\begin{array}{l}1447 \pm 94 \mathrm{~nm} \\
\quad(\mathrm{DI} \text { water })\end{array}$ & $-15.2 \pm 0.2 \mathrm{mV}$ & $\begin{array}{l}\text { pH } 724 \text { h: } 0.4 \%, 14 \text { days: } \\
0.1 \% \text {; } 5 \text { H } 524 \text { h: } 1.7 \%, 14 \\
\text { days: } 1.9 \%\end{array}$ \\
\hline
\end{tabular}

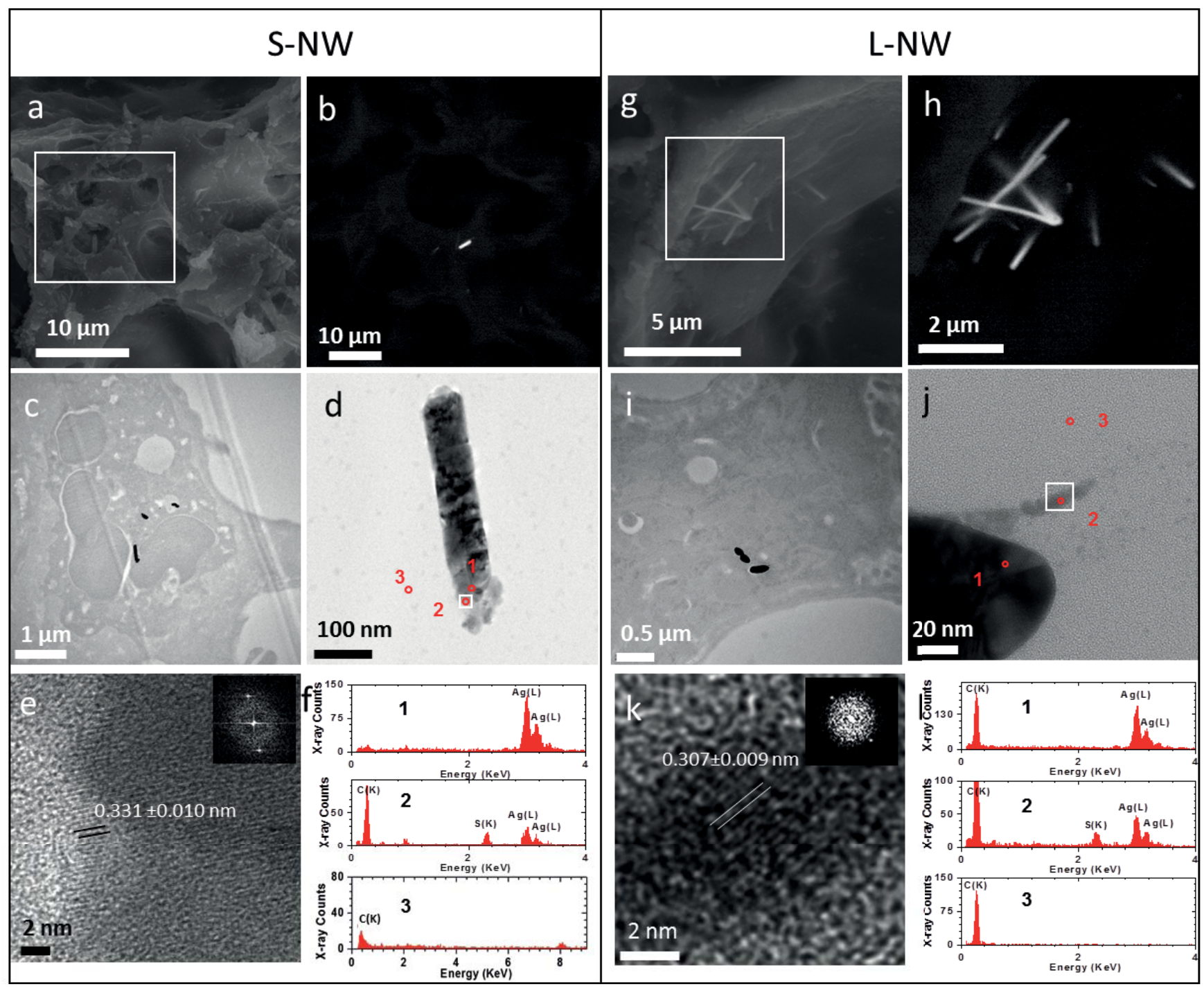

Figure 2. SEM and AEM analysis of lung samples $24 \mathrm{~h}$ after post-instillation of $(\mathrm{a}-\mathrm{f}) \sim 1 \mu \mathrm{m} \mathrm{S}-\mathrm{NW}$ and $(\mathrm{g}-\mathrm{l}) 10 \mu \mathrm{m} \mathrm{L}-\mathrm{NW}$. (a, g) Low-resolution secondary electron SEM imaging and $(b, h)$ corresponding backscattered electron imaging of the boxed areas in (a, $g)$ showing the presence of S-NW and L-NW in alveolar regions, respectively. (c, i) BFTEM imaging shows the localization of S-NW and L-NW inside type II epithelial cells, magnified views are shown in $(b, j)$, respectively. $(d, j)$ The morphology of S-NW and L-NW, respectively; featured by etched surface and nanostructure formation on the surface. (e, $k$ ) HRTEM images from the boxed region in $(d, j)$ reveal lattice spacings of $0.331 \pm 0.010 \mathrm{~nm}$ and $0.307 \pm 0.009 \mathrm{~nm}$, corresponding to monoclinic $\mathrm{Ag}_{2} \mathrm{~S}(012)$ and (111) planes (ref no. 00-014-0072), respectively. The insets are FFT patterns of the corresponding HRTEM images. ( $f, 1)$ EDX spectra collected from areas as marked in $(d, j)$ respectively, indicate the NW is Ag rich in composition. The structure protruding from the surface of the nanowire is sulfur and silver rich in composition. Only carbon signals were detected from the background. The integrated $S$ to $\mathrm{Ag}$ molar ratio extracted from EDX spectra collected from positions in panels $\mathrm{f}$ and $\mathrm{I}$ (area 2 , in each case) were $0.91 \pm 0.20$ and $0.54 \pm 0.11$, respectively.

and an average diameter of $72 \pm 36 \mathrm{~nm}$ (Figure 1d), as measured by TEM. High-aspect ratio long silver nanowires (L-AgNWs) (Figure 1e,f) have a similar average diameter of $73 \pm 37 \mathrm{~nm}$ (Figure 1h), but a longer average length of $10.5 \pm 8.5 \mu \mathrm{m}$ (Figure 1g). From dynamic light scattering (DLS) measurements, the average hydrodynamic sizes of the S-AgNWs and L-AgNWs were $807 \pm 66 \mathrm{~nm}$ and $1447 \pm 94 \mathrm{~nm}$, respectively. For both types of AgNWs, the measured hydrodynamic sizes were not representative of the sizes measured by TEM. This is because NW size information in DLS is obtained by measuring the 


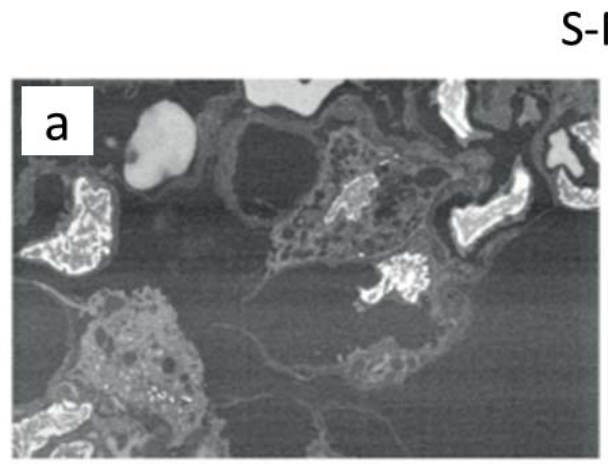

S-NW
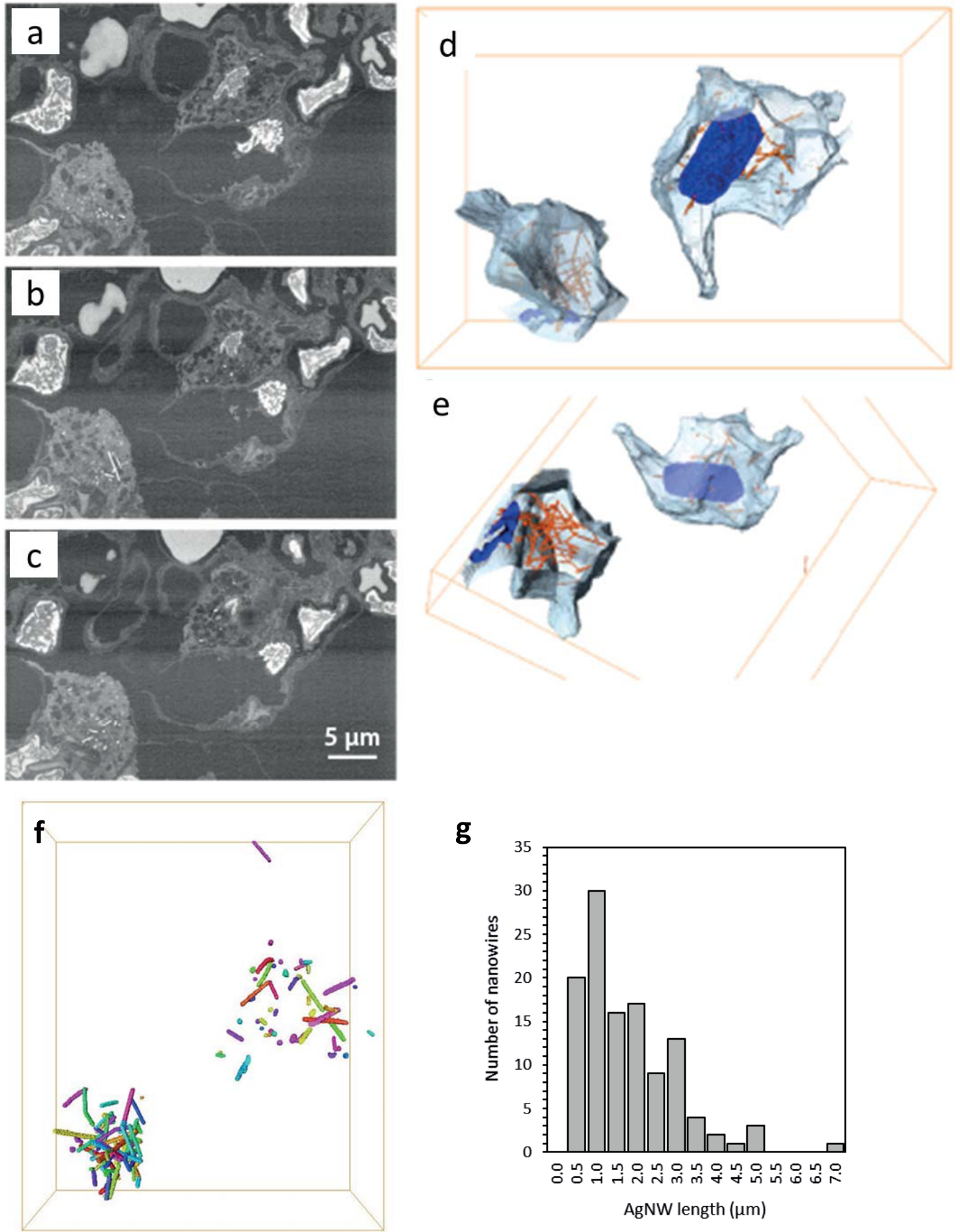

g

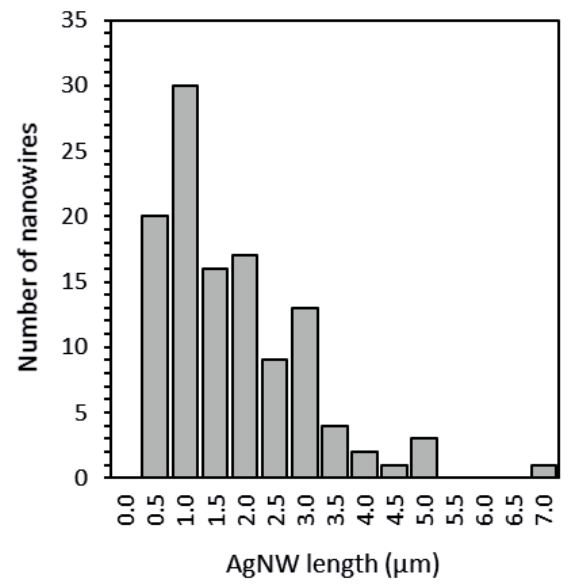

Figure 3. 3D SEM imaging of S-NW in lung $24 \mathrm{~h}$ after post-instillation. $(\mathrm{a}-\mathrm{c})$ Selected SEM images from a serial block face data set taken over a volume of $40 \times 40 \times 11 \mu \mathrm{m}$ as well as a visualization of the two cells within this region containing S-NWs. (d, e) A reconstructed 3D volume reconstruction generated using serial block face FIB-SEM using an in situ ultramicrotome, showing the S-NWs within a type II epithelial cell. (f) Individual S-NW in Figure 2g,h have been identified by a combination or watershed filtering and manual segmentation and are distinguished here by color. (g) Histogram showing the lengths of internalized S-NWs.

particle's diffusion coefficient, which in the case of high-aspect ratio NWs has both a translational and rotational component. The measured sizes may therefore be interpreted only as the sizes of spherical $\mathrm{Ag}$ particles that would have the same diffusion coefficient as S-AgNWs and L-AgNWs. However, using light microscopy, we have previously shown that in the absence of pulmonary surfactant components, AgNWs did not agglomerate during up to 7 days of incubation. ${ }^{14}$ In the case of L-AgNWs, the interplanar spacing's measured from selected area electron diffraction (SAED) patterns were $0.235,0.204$ and $0.144 \mathrm{~nm}$, 
Control

$\mathrm{AgNO}_{3}$

Ag S-NW

Ag L-NW

Inflammation: 24 hours
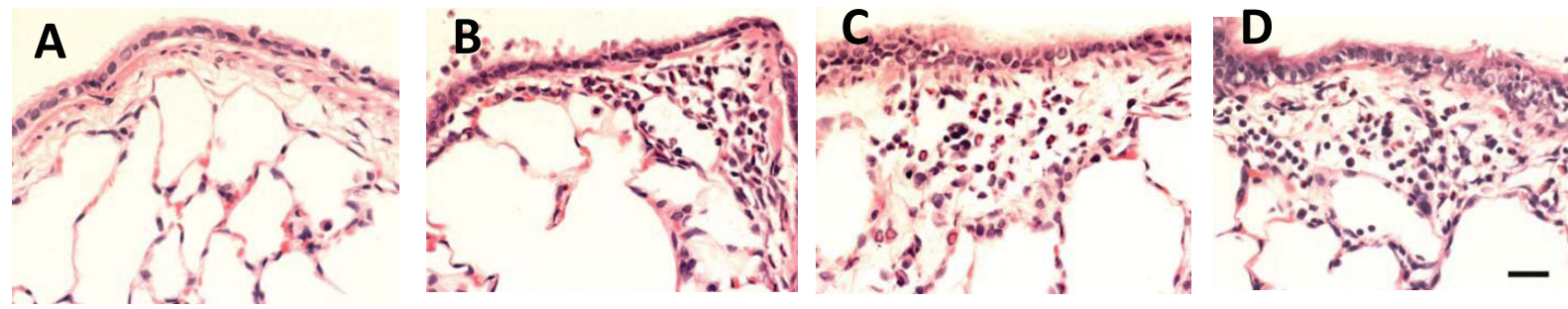

\section{Silver staining: lung}
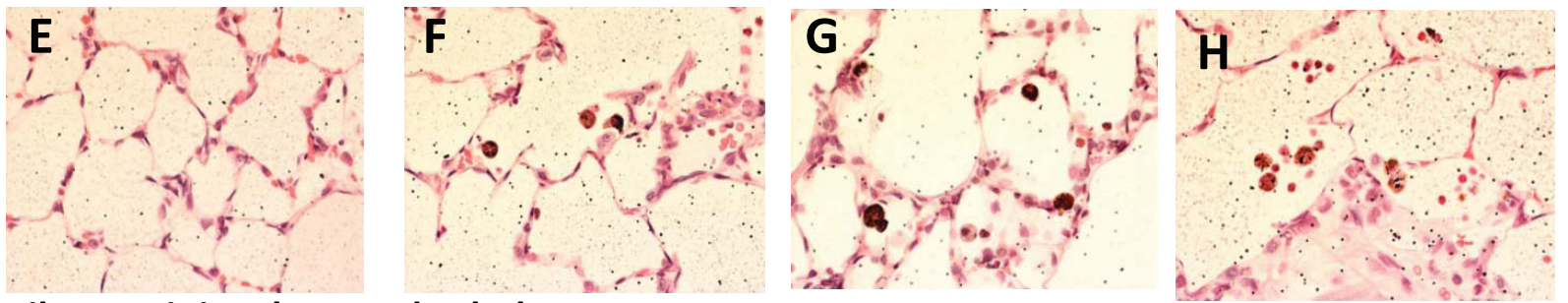

Silver staining: lung and subpleura
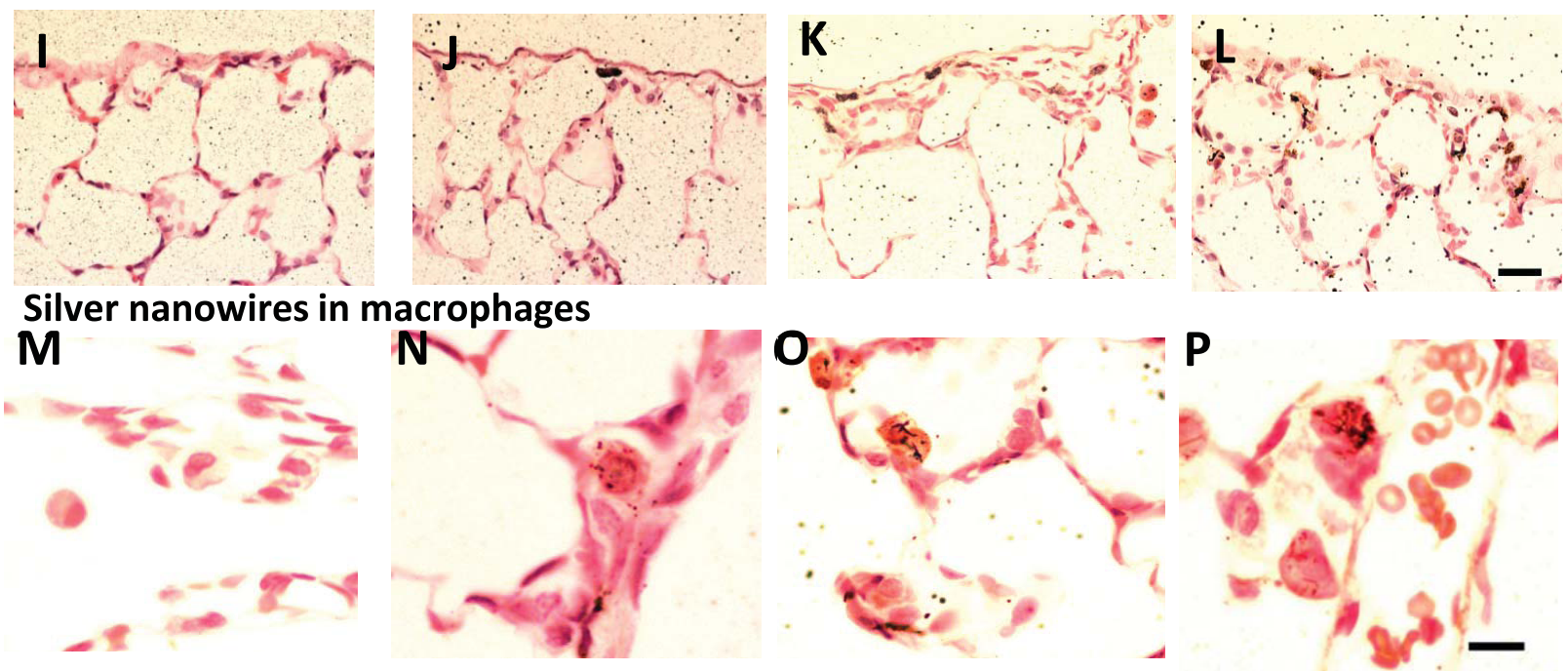

Figure 4. Panels A-D: Hematoxylin and eosin-stained lung Sprague-Dawley sections at $24 \mathrm{~h}$ post-treatment show no inflammatory response in air control (A) and foci or patchy of inflammatory cells infiltrated in bronchial wall and alveolar septa in $\mathrm{AgNO}_{3}$-exposed (B), S-NW (C), and L-NW (D). The inflammatory cells macrophages (internal scale bar $=20 \mu \mathrm{m}$ for all). Panels E-H: Silver enhancing and hematoxylin/eosinstained Sprague-Dawley rat lung sections at $24 \mathrm{~h}$ post-treatment show an absence of signal in (E) air control, and silver-positive cells alveolar space is seen as black or black-brown positivity in $\mathrm{AgNO}_{3}\left(\mathrm{Ag}^{+}, \mathrm{F}\right), \mathrm{S}-\mathrm{NW}(\mathrm{G})$, and $\mathrm{L}-\mathrm{NW}(\mathrm{H})$ instillation (internal scale bar $=20 \mu \mathrm{m}$ for all). Panels I-L: Silver enhancing and hematoxylin/eosin-stained pleural and subpleural regions of Sprague-Dawley rat lung sections at $24 \mathrm{~h}$ show an absence of signal in air control (I), a few black silver-positive cells after $\mathrm{AgNO}_{3}$ instillation (J), and some of black or black-brown silver-positive cells after S-NW instillation (K), and more silver-positive cells deposited in subpleural connective tissue or alveolar space or septa in L-NW-instilled lungs (L) (scale bar $=20 \mu \mathrm{m}$ for all). Panels M-P: High-power view of alveolar macrophages with silver enhancing and hematoxylin/eosin-stained containing remnants of AgNWs. (N) After instillation of $\mathrm{AgNO}_{3}$ at $24 \mathrm{~h}(\mathrm{O})$ shows a macrophage after instillation of $1 \mu \mathrm{m} \mathrm{S}$-NWs at $24 \mathrm{~h}$, while $(\mathrm{P})$ shows a macrophage after instillation of $10 \mu \mathrm{m}$ L-NWs at 7 days $($ scale bar $=10 \mu \mathrm{m})$.

corresponding to the (111), (200), and (220) planes of metallic silver (ref no. 01-087-0597). TEM energy dispersive X-ray (EDX) spectra collected from several L-AgNWs showed that they consisted of pure Ag, confirming the absence of impurities from the synthesis product, and that no sulfidation had occurred on the material. A summary of the properties of the AgNWs used is given in Table 1.

2D and 3D Imaging of Nanowires in the Lung. Since we had seen various types of staining in cells and the lung in response to the AgNWs, we were interested in the chemical speciation of silver in the lung tissue alveolar Type II (ATII) cells and the macrophages, especially due to the possibility of transformative processes such as dissolution and sulfidation, which have so far only been seen in in vitro exposures of lung cells for both AgNWs as well as for AgNPs. ${ }^{13,18}$ We used a combination of $2 \mathrm{D}$ and 3D SEM, high resolution phase contrast imaging (HRTEM), and EDX to visualize the location of the AgNWs within the cells and to characterize their chemistry. Imaging was performed at $24 \mathrm{~h}$ after instillation of the S-AgNWs and L-AgNWs. The data are shown in Figures 2 and 3.

Silver Nanowires. Both the S-AgNWs and L-AgNWs were found in the alveoli using SEM and TEM; the backscattered 
electron detector was used in the SEM to generate contrast from the AgNWs (Figure 2a,b,g,h). The AgNW samples were analyzed by spatially resolved analytical EM techniques to study whether the AgNWs had dissolved or transformed to other compounds in the alveoli. Changes to the morphology of the AgNWs were observed at the end of the S-AgNWs located inside an ATII cell (Figure 2c,d). The interplanar spacing measured from a highresolution (HR)TEM image acquired from the tip of the S-NW (Figure 2e) was $0.331 \pm 0.010 \mathrm{~nm}$, corresponding to the (012) plane of monoclinic silver sulfide $\mathrm{Ag}_{2} \mathrm{~S}$ (ref no. 00-014-0072). STEM-EDX analysis showed that $\mathrm{Ag}_{2} \mathrm{~S}$ was detected on the surface of the S-AgNWs by STEM-EDX (Figure 2f, spectrum 2); the core of the S-AgNWs consisted of pure Ag (Figure 2f, spectrum 1). Only carbon was detected from the background (Figure 2f, spectrum 3). Partially sulfidised AgNWs were also found with the L-AgNWs inside the ATII cells (Figure $2 \mathrm{~g}-1$ ). In $2 \mathrm{D}$ projection images, it was not possible to measure the length of the S-AgNWs, therefore we used serial block face SEM (Figure $3 \mathrm{a}-\mathrm{e}$ ) to generate $3 \mathrm{D}$ volume reconstructions of the AgNW inside the structural cells (Figure 3d,e; Supporting Movie). Since dissolution and transformation were the same for S-AgNWs and L-AgNWs, their morphological and chemical evolution inside the lung in vivo was examined by 3D SEM for the S-AgNWs only. Figure $3 a-c$ show selected SEM images from a serial block face data set taken over a volume of $40 \times 40 \times 11 \mu \mathrm{m}$ as well as a visualization of the two cells within this region containing S-AgNW. After segmentation of individual S-AgNW, their length distribution was quantified. The histogram of internalized S-AgNW lengths revealed that the S-NW contained within the cells were significantly shorter compared to the instilled material $(p<0.05)$ (Figure 3f,g).

Lung Inflammation. Following instillation with AgNWs, there was a mild to moderate inflammation with infiltration of inflammatory cells in the bronchial and vascular walls and alveolar septa and also exudates in the alveolar space in SpragueDawley rat lungs (Figure 4A-D). Overall, tissue inflammation scores were significantly increased in lungs of all silver-instilled groups at day 1 , and this subsequently fell at 7 and 21 days (Figure 5A). Inflammatory cells were distributed patchily and consisted mainly of neutrophils, eosinophils, monocytes/macrophages, and also of some lymphocytes. The inflammatory responses were similar across the AgNW groups. Foreign body reactions, such as giant foreign body macrophages, were not observed in the lungs instilled with AgNWs.

Localization and Quantification of Silver in the Lung. Following instillation of AgNWs, aggregated Ag particles were visible in tissue macrophages and also in alveolar epithelial cells (Figure $4 \mathrm{E}-\mathrm{H}$ ). Some of the macrophages had diffuse brownstaining radiating away from the black particles, indicating that the AgNPs were likely to be dissolving. Most of time, the macrophages had fully phagocytosed the S- and L-AgNWs. The silver-laden macrophages were sparse but located throughout the lung tissue, mainly in alveolar spaces and septa (Figure 4E-H) and some in the patchy inflammatory areas within the walls of the bronchi or blood vessels. S- and L-AgNWs were found in similar locations in the lung at $24 \mathrm{~h}$. Cells containing silver were also found in subpleural connective tissue and in the adjacent subpleural alveolar spaces and septa (Figure 4I-L). Remarkably, individual, intact alveolar macrophages contained remnants of the AgNWs at $24 \mathrm{~h}$ and 7 days after instillation suggesting that there was no frustrated phagocytosis (Figure $4 \mathrm{E}-\mathrm{H}, \mathrm{M}-\mathrm{P}$ ). The L-AgNW-instilled lungs had more Ag+ve macrophages situated
A

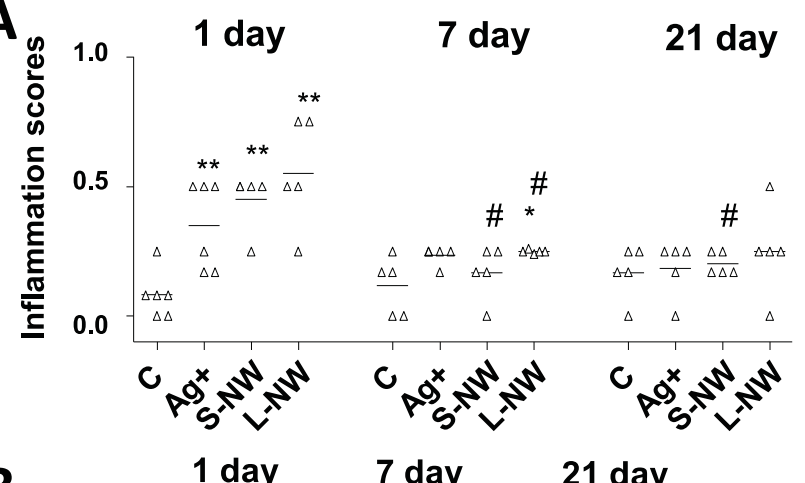

B
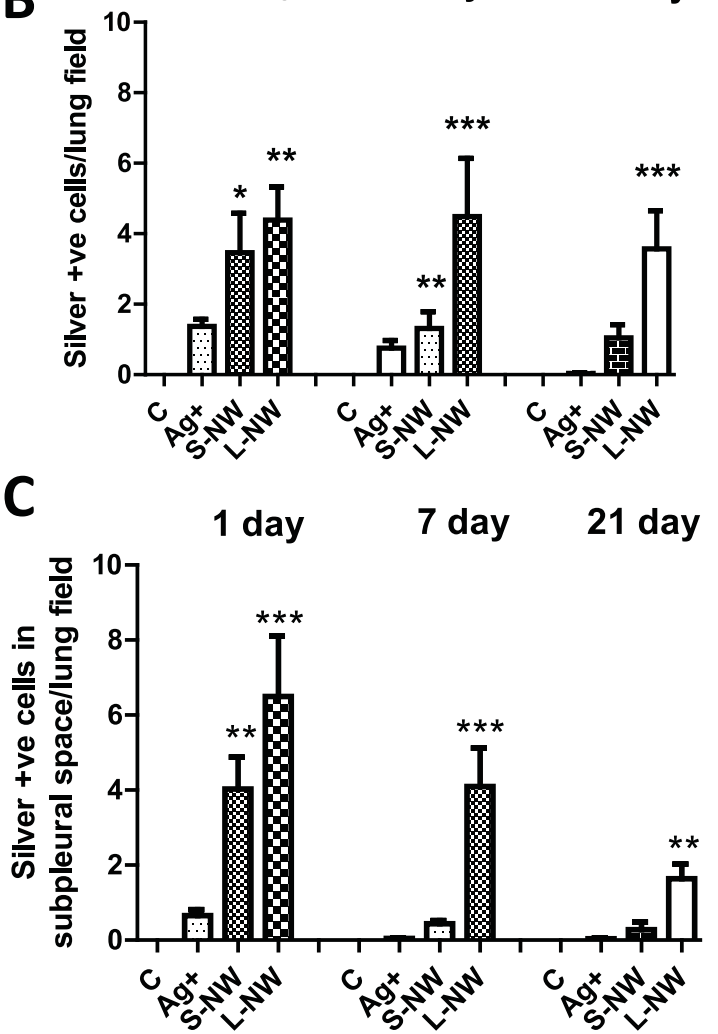

Figure 5. (A) Individual Inflammation scores of lungs of rats instilled with control distilled water $(C)$, silver nitrate solution $\left(\mathrm{Ag}^{+}\right), \mathrm{S}-\mathrm{NW}$, or L-NW after 1, 7, or 21 days after instillation. (B, C) Counts of positive-staining cells for silver in lung tissue $(B)$ or in the subpleural tissue (C) at 1, 7, or 21 days after instillation. Data shown as mean \pm SEM $* p<0.05, * * p<0.01, * * * p<0.001$ compared to control C. $\# p<0.05$ compared to day 1 .

at the pleural interface and in subpleural alveoli, compared with that observed following exposure to the S-AgNWs (Figure 5C).

The number of cells containing silver particles, quantified using the autometallographic method, across the lung excluding the subpleural space and in the subpleural space are shown in Figure 5B,C, respectively. There was a significant increase in $\mathrm{Ag}^{+}$ counts in the lungs with both S-AgNWs and L-AgNWs at $24 \mathrm{~h}$ compared to controls or to instillation of silver nitrate. There was then a decrease in Ag+ve cells after S-AgNW instillation at days 7 and 21 . By contrast, the Ag+ve cells remained elevated after $\mathrm{L}-\mathrm{AgNW}$ instillation at these time points. Interestingly, in the subpleural space, while both L-AgNWs and S-AgNWs exposure led to an increased number of silver-containing cells, the L-AgNWs induced the greatest change at $24 \mathrm{~h}$. At 7 and 21 days, 

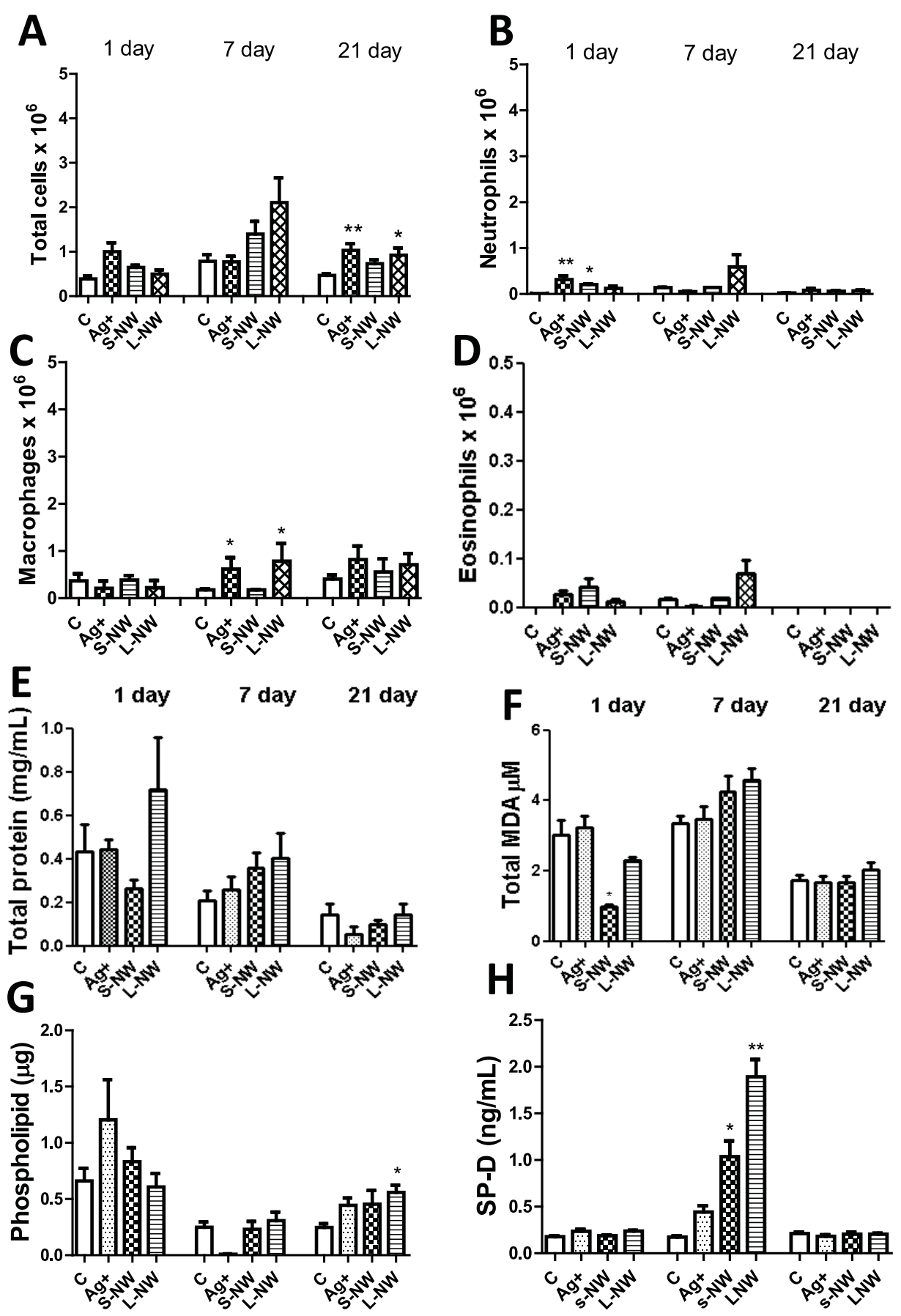

Figure 6. (A-D) Total cell counts and differential cell counts in BALF after instillation of control distilled water $(\mathrm{C})$, silver nitrate solution $\left(\mathrm{Ag}^{+}\right)$, S-NW, or L-NW after 1, 7, or 21 days after instillation. (E-H) Levels of total protein (E), MDA (F), phospholipid (G), and SP-D (H) after $1 \mathrm{mM}$ citrate $(\mathrm{C})$, silver nitrate solution $\left(\mathrm{Ag}^{+}\right)$, S-NW, or $\mathrm{L}-\mathrm{NW}$ instillation at days 1,7 , or 21 . Data shown as mean $\pm \mathrm{SEM} * p<0.05$ and $* * p<0.01$ compared to (C).

but only after L-AgNW instillation, significant numbers of Ag+ve cells were still present.

BAL Inflammation. There was a small increase in neutrophils after S-AgNW instillation at day 1, accompanied by no other inflammatory changes at days 7 and 21 (Figure 6A-D). By contrast, there was no effect of L-AgNWs at day 1 , but there was an increase in macrophage numbers at day 7 , with a small nonsignificant eosinophilic response only at day 7 . Following silver nitrate instillation, there was a small increase in neutrophils at day 1 and in macrophages at day 7 and day 21 .
Oxidative Stress and Surfactant Protein Levels. There were no changes in bronchoalveolar lavage (BAL) total protein after AgNW instillation or silver nitrate instillation at any time point (Figure 6E). There was also no change in malonaldehyde (MDA) levels at 1 day postexposure with silver nitrate, but the S-AgNWs caused a significant reduction in MDA at day 1 only and both S- and L-AgNWs nonsignificantly increased MDA levels at day 7. Levels of MDA were unchanged at day 21 (Figure 6F). BAL total phospholipid was not significantly increased for any of the $\mathrm{Ag}$ instillations at 1 day postexposure. At 7 days, instilled 
silver nitrate induced a decrease in phospholipid. L-AgNWs induced significant increases in total phospholipid levels at day 21 (Figure 6G). The most marked increases in SP-D levels occurred after 7 days for both S-AgNWs and L-AgNWs, with the highest increase for L-AgNWs; silver nitrate instillation caused a small nonsignificant increase at day 7. By 21 days, SP-D had returned to baseline values (Figure $6 \mathrm{H}$ ).

BAL Chemokines and Cytokines. Instillation of silver nitrate induced increases in the cytokines KC, MIP- $1 \alpha$, MCP-1, TNF- $\alpha$, interleukin (IL)-6, IL- $1 \beta$, and IL-18 (but not in IFN $\gamma$, IL-17A or IL-13) at day 1, with these levels returning to baseline by day 7 (Figure 7). The profile of release of cytokines was different between the short and long nanowires: the S-AgNWs caused the release of KC, IL-18, and IL-13, while L-AgNWs caused a significant release of $\mathrm{KC}$, IL- $1 \beta$, MIP- $1 \alpha$, and IL-6, with a nonsignificant increase in IL-17A, MCP-1, or TNF $\alpha$. The increased levels of cytokine/chemokine release were normal by day 7. L-AgNWs induced an increase in IL-18 and IFN $\gamma$ at 21 days.

Lung Mechanics. Large airway resistance $(\mathrm{Rn})$ did not change after silver nitrate or S-AgNW or L-AgNW instillation. Rn responsiveness to acetylcholine was increased at $1(P<0.05)$ and $7(P<0.01)$ days after L-AgNW treatment compared to the control response (Figure 8). There were no increases in tissue resistance $(G)$ noted after instillation of S- or L-AgNWs or $\mathrm{Ag}^{+}$, and there was no increase in responsiveness to acetylcholine either (Supporting Information, Figure S1). Tissue elastance $(H)$ was elevated at 1 day but returned to baseline by 7 days after silver nitrate or S-AgNW or L-AgNW instillation, and there was a small increase in response to the highest dose of acetylcholine at days 1 and 7 for the L-AgNWs (Figure S2).

We investigated the fate and the toxic effects of instilled AgNWs in rat lung. Most interestingly, we showed that a small fraction of the AgNWs can penetrate the epithelial cell lining particularly in ATII cells, and within this cell type they dissolve and $\mathrm{Ag}_{2} \mathrm{~S}$ nanoparticles reprecipitate on their surface. On the other hand, aggregated AgNWs, through the effect of the airway lining fluid containing phospholipids and surfactant proteins, were taken up by lung macrophages. These nanowires were found to be shorter within the macrophages and epithelial cells. Silver-containing cells were increased not only in the alveolar compartment but also in the subpleural space within the first $24 \mathrm{~h}$ for both S- and L-AgNWs; however, only for the L-AgNWs was there persistence of silver-positive cells beyond day 1 . There was a relatively mild transient degree of inflammatory response with little evidence of an oxidative stress or protein exudation, but associated with an acute release of cytokines. The mild inflammatory response may be linked to the dissolution and transformation of the surface of the $\mathrm{AgNWs}$ to $\mathrm{Ag}_{2} \mathrm{~S}$ seen intracellularly, here in ATII cells, and also inside J774 macrophage cells in vitro, ${ }^{16}$ and hence their inactivation leads to a reduced dissolution rate of the nanowires.

The inflammatory responses that we observed with the AgNWs were milder when compared to that previously observed with silver nanospheres in the same species and when administered intratracheally with an even lower amount of silver of $0.1 \mathrm{mg} / \mathrm{kg}$. ${ }^{9}$ We observed an acute effect in the lungs occurring at day 1 only for both nanowires, and intraluminally, there was an acute neutrophilic response with the S-AgNWs with a more delayed response with the L-AgNWs at day 7 with predominant macrophage response. The cytokine response in BAL showed that out of the acute phase cytokines measured, a differential increase at day 1 of IL-18 with the S-AgNWs and of IL-6, IL-1 $\beta$,
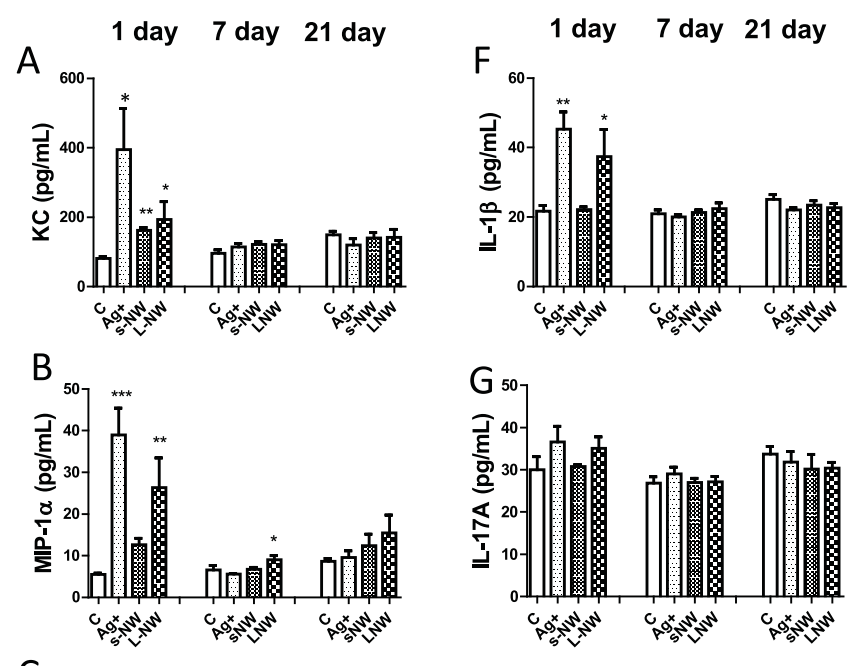

C
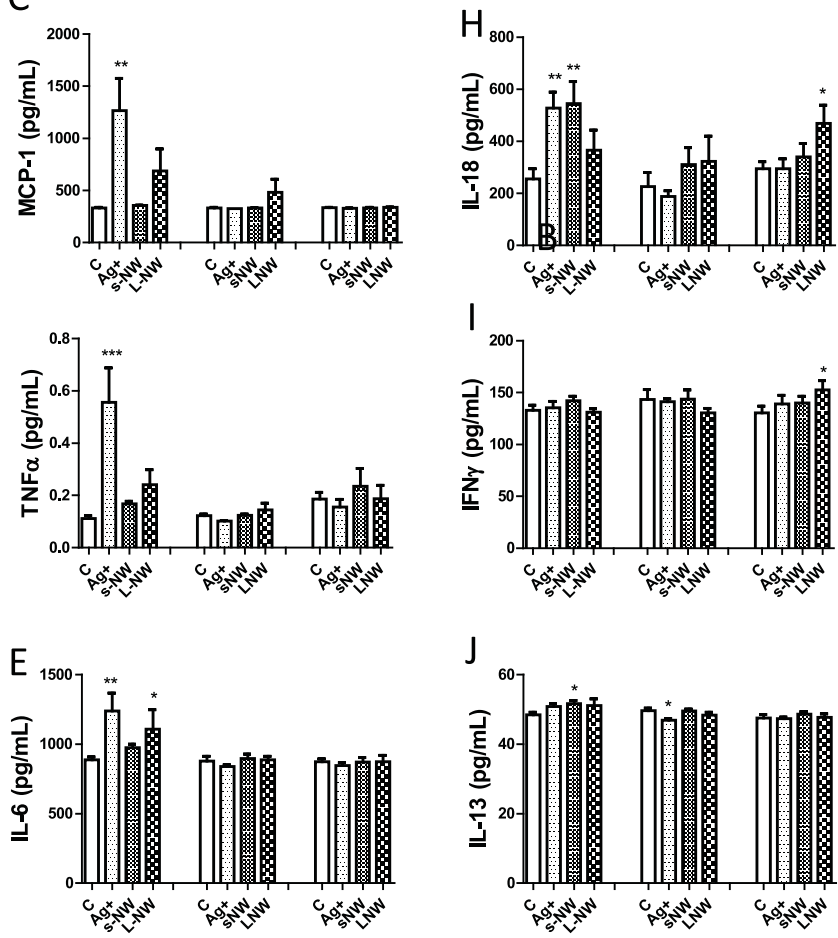

Figure 7. Cytokine levels in BALF after control distilled water (C), silver nitrate solution $\left(\mathrm{Ag}^{+}\right), \mathrm{S}-\mathrm{NW}$, or L-NW instillation at days 1,7 , or 21. Data shown as mean \pm SEM $* p<0.05$, $* * * p<0.01$, and $* * * p<$ 0.001 compared to (C). IFN $\gamma$ : interferon- $\gamma$; IL-i $\beta$ : interlukin- $1 \beta$; IL-6: interleukin-6; IL-13: interleukin-13; IL-17A: interleukin-17A; IL-18: interleukin-18; KC: keratinocyte cytokine; MCP-1 (or CCL2): monocyte chemotactic protein-1; MIP-1 $\alpha$ (or CCL3): macrophage inflammatory protein- $1 \alpha$; TNF $\alpha$ : tumor necrosis factor- $\alpha$.

and MIP- $1 \alpha$ with the L-AgNWs. IL-18 is known to promote neutrophil activation, reactive oxygen species, cytokine release, and degranulation ${ }^{19,20}$ and, therefore, could underlie the mild neutrophilic responses seen with S-AgNWs, but there was no evidence of oxidative stress or other cytokines released. On the other hand, MIP $1 \alpha$ is a chemoattractant for inflammatory cells such as monocytes, T cells, and eosinophils, while IL- 6 and IL- $1 \beta$ are also mediators of monocytic and neutrophilic inflammation that could underlie the acute inflammatory phase response in lungs and the more delayed response in BAL fluid (BALF) after instillation of long NWs. Thus, the L-AgNWs caused a longer lasting inflammatory response associated with a greater variety of 

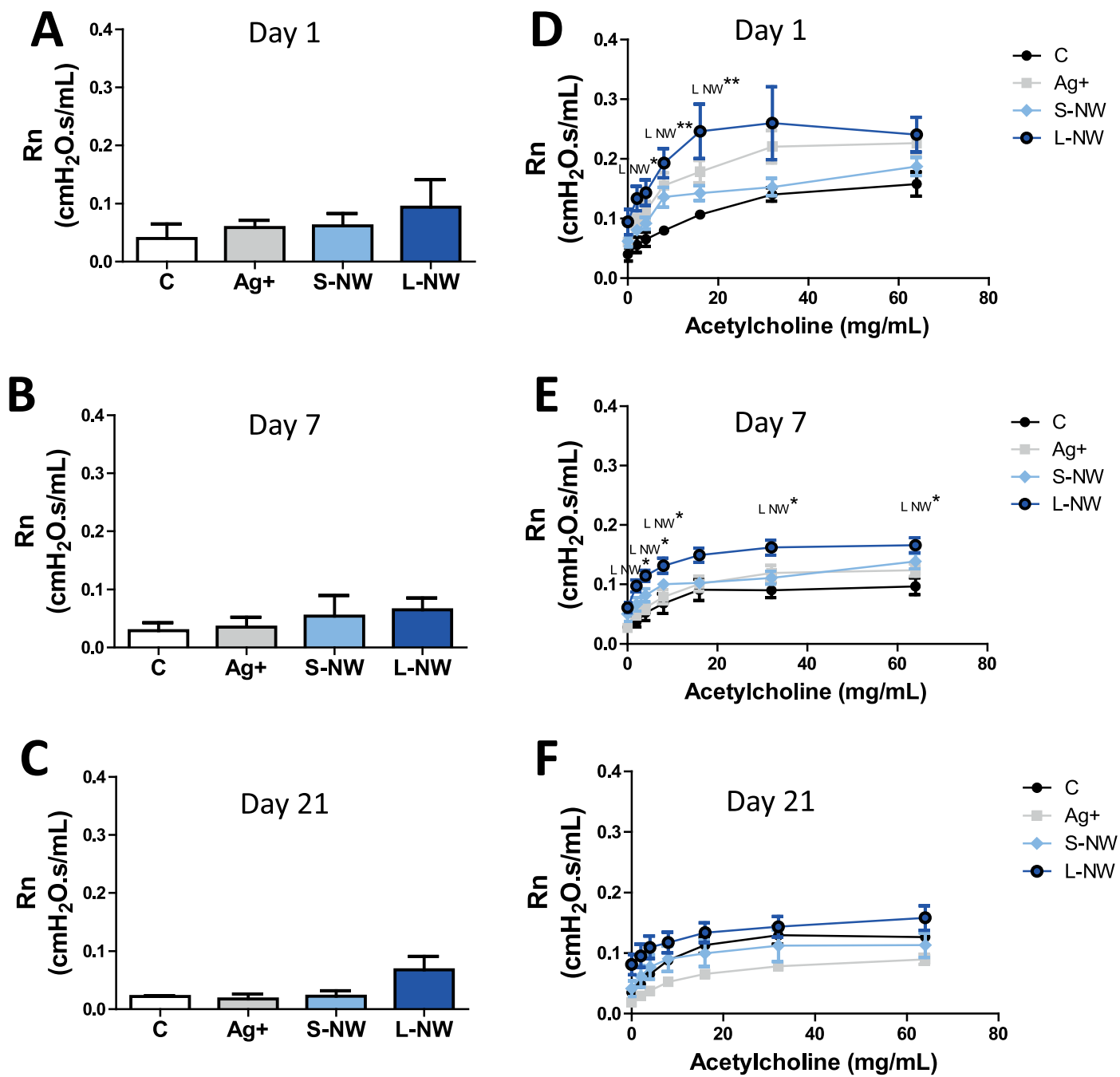

Figure 8. Large airway resistance $(\mathrm{Rn})(\mathrm{A}-\mathrm{C})$ and concentration-response curves to acetylcholine $(\mathrm{D}-\mathrm{F})$ after instillation of control distilled water $(\mathrm{C})$, silver nitrate solution $\left(\mathrm{Ag}^{+}\right), \mathrm{S}-\mathrm{NW}$, or $\mathrm{L}-\mathrm{NW}$ at days 1,7 , or 21 . Data shown as mean $\pm \mathrm{SEM} * p<0.05$ and $* * p<0.01$ compared to zero acetylcholine concentration.

cytokine response than the S-AgNWs, compatible with the longer persistence of silver-positive cells seen with the L-AgNWs.

By contrast, we have previously shown that instillation of PVP-coated AgNPs of $20 \mathrm{~nm}$ diameter induced a high degree of neutrophilia and levels of KC at day $1,{ }^{9}$ levels similar to that seen after instillation of $\mathrm{AgNO}_{3}$ in the present study, together with an increase in oxidative stress, as evidenced by an increase in malonyldehyde at day 1 . Taken together, this suggests that the dissolution of AgNWs seen here and in situ in our previous work ${ }^{14}$ may be responsible for the differential inflammatory and oxidative stress changes because the rate of dissolution from AgNWs would be much slower compared to dissolution of silver nanospheres, since the surface area:volume ratio of the AgNPs is 5.27- and 5.36-fold greater than that of the AgNWs, short and long wires, respectively. It also follows that the lesser dissolution rate of the L-AgNWs compared to the S-AgNWs for the same amount of silver may contribute in part to its greater persistence.

Despite the attenuated response in terms of inflammation, there was an increase in airway hyperresponsiveness to acetylcholine seen maximally at day 1 and absent by day 21 after instillation of L-AgNWs but not of S-AgNWs. This response is reflective of the large airways and not of the small airways or lung parenchyma where most of the tissue-associated AgNWs were localized to ATII cells. In comparison, silver nanospheres of $20 \mathrm{~nm}$ in diameter and PVP-capped also increased airway hyperresponsiveness at day $1 .^{7}$ Whether this could result from the direct interaction of the AgNPs with airway smooth muscle cells in the large airways, the site of airway hyperresponsiveness, is unclear. Again, it is likely that this effect of L-AgNWs on bronchial hyperresponsiveness and not of the S-AgNWs may be the result of the greater persistence of the L-AgNWs. Further studies of the direct interactions of airway smooth muscle cells, the putative site of airways hyperresponsiveness, with AgNWs are warranted, and the effect of silver ions also examined. Importantly, from the medical point of view, our observation indicates that these AgNWs could also predispose those exposed to AgNWs to the development of asthma, which is characterized by airways hyperresponsiveness.

Using quantification by the autometallographic method, we showed that both types of AgNWs accessed the alveoli following instillation. Electron microscopy confirmed that some of the S- and L-AgNWs were internalized by a small number of ATII cells. Intracellularly, transformation of the $S$ and L-AgNWs was observed, with precipitation of $\mathrm{Ag}_{2} \mathrm{~S}$ on their surface and as secondary $\mathrm{Ag}_{2} \mathrm{~S}$ nanoparticles. In our previous work, incubation of S-AgNWs with a commercially available porcine-derived 
surfactant preparation (Curosurf), as well as separate components of murine lung lining fluid, provided no evidence of sulfidation of the AgNWs in any of these components. ${ }^{14}$ Therefore, we assume that, in the present work, this transformation has occurred intracellularly, following uptake of the AgNWs by ATII cells. Consequently, the reduction in the length distribution of internalized S-AgNWs, compared to the as-synthesized S-AgNWs, may be due to this dissolution-reprecipitation process that leads to disintegration of their original structure and fragmentation into shorter parts. In support of this hypothesis, in vitro uptake of AgNWs by immortalized human alveolar type 1-like epithelial cells led to dissolution and sulfidation of the AgNWs. ${ }^{18}$ This process of NP sulfidation has also been observed when AgNPs were incubated with a J774 macrophage cell line in vitro. ${ }^{16} \mathrm{We}$ suggested that sulfidation occurred through the action of sulfide species, including $\mathrm{H}_{2} \mathrm{~S}, \mathrm{HS}^{-}$, or $\mathrm{S}^{2-}$, which are present inside human lung tissues. Since no evidence of cytotoxicity was observed, we proposed that the precipitation of $\mathrm{Ag}^{+}$ions released from the AgNWs as highly insoluble $\mathrm{Ag}_{2} \mathrm{~S}$ may act as a detoxification mechanism that could limit their short-term toxicological effects. A recent study employing synchrotron-based transmission X-ray microscopy (TXM) and X-ray adsorption near edge spectroscopy (XANES) shows that, during uptake and exocytosis from THP-1 macrophages, $20 \mathrm{~nm}$ AgNPs were gradually transformed, first into $\mathrm{Ag}-\mathrm{O}-$ and then $\mathrm{Ag}-\mathrm{S}-$ forms, ${ }^{21}$ correlating with key events of cellular toxicity, suggesting that the particulate form of AgNPs and their degraded forms play synergistic roles in mediating AgNP cytotoxicity. Using XANES, $\mathrm{Ag}^{+}$ions released from $60 \mathrm{~nm}$ AgNPs inside primary murine macrophages were shown to form complexes with thiolate groups, with glutathione identified as the most likely ligand. ${ }^{22}$ However, these studies need to be confirmed using AgNWs.

Furthermore, the majority of the AgNWs were not found in alveolar type 1 epithelial cell (ATI) or ATII cells, but instead aggregated AgNWs were visible in tissue macrophages (Figure 4E-H), which in most cases had fully phagocytosed the S- and L-AgNWs. Therefore, a large proportion of AgNWs reaching the deep lung would be cleared by alveolar macrophages. In our in vitro work, ATII secretions (containing both the complete lipid and protein complement of human pulmonary surfactant) reduced AgNW uptake by ATI cells. ${ }^{13}$ This reduction in uptake possibly involved specific binding of SP-A and SP-D to the AgNWs, ${ }^{13}$ which we have found induces AgNW agglomeration. ${ }^{14} \mathrm{~A}$ change in the agglomeration state of AgNWs could affect the response of different cell types, improving their uptake efficiency by macrophages but reducing it by epithelial cells. This effect may have therefore led, in part, to the large number of aggregated S- and L-AgNWs observed here in tissue macrophages, but not in epithelial cells. Similarly, in a recent study by Silva et al., instillation of AgNWs of two different lengths (2 and $20 \mu \mathrm{m})$ in rats led to significant numbers of Ag-positive macrophages from day 1 through to day $21 .^{12}$

Change in SP-D protein is an important factor in influencing nanoparticle interaction with the lung lining fluid that in turn may determine their uptake by alveolar epithelial cells and also the aggregation state of the nanoparticles, which will determine their phagocytosis by macrophages. ${ }^{23}$ We saw a prominent increase in SP-D in BALF at day 7 after both the S- and L-NWs, suggesting increased ATII synthesis and/or release of SP-D in response to NW exposure and possibly related to the observed preferential epithelial localization of the nanowires. SP-D is an important immunomodulatory protein which, for example, has been shown to subdue Th2-type responses, modulating macrophage and dendritic cell function as well as T-cell-dependent inflammatory events. Importantly, SP-D also plays an important role in pathogen clearance from the lung, through specific binding to microorganisms and enhancing macrophage uptake. SP-D adsorption by $\mathrm{AgNWs}^{13}$ leading to increased aggregated AgNWs may be favored by the presence of high levels of SP-D in the bronchoalveolar space, ${ }^{24}$ thus enhancing the clearance of AgNWs. Thus, our work indicates that the role of the different components of surfactant in moderating the aggregation, uptake, translocation, and clearance of S- and L-AgNWs (and other nanomaterials with different aspect ratios) is important, also impacting immune defense mechanisms. On-going studies in our laboratory aim to understand these mechanisms in greater depth to better anticipate any impact of human exposure.

Exposure to both S- and L-AgNWs also led to an increased number of silver-containing cells in the lungs and in the subpleural space, with the highest effect observed for L-AgNWs at $24 \mathrm{~h}$. By 7 and 21 days, while S-AgNWs had disappeared from this site, L-AgNWs still persisted. In the work by Silva et al., AgNWs of both lengths were found in the pleural regions at day 1, but only nonparticulate Ag could be detected at days 7 and $21{ }^{12}$ These findings suggest that some of the AgNWs deposited in the lungs move through the pleura. There is evidence that a fraction of any type of particles that have deposited in the distal regions of the lung can translocate to the pleural space. ${ }^{25}$ The pathway by which these particles reach the pleura from the lung parenchyma may involve lymphatic flow from the parenchyma to the pleural space, but it is incompletely elucidated. Clearance of particles or fibers from the pleural space appears to be length dependent. This clearance occurs through passive removal in the flow of pleural fluid out of the pleural space into the lymphatic system, with stomata or pores $(\sim 3-10 \mu \mathrm{m}$ in diameter) acting as a sieve for drainage from the pleural space. Consequently, as has been previously observed for carbon nanotubes, the movement of long fibers is impeded by the size of the stomata, causing them to lodge in the pleural tissue, where they may exert pathogenic effects over a long period of time. ${ }^{26}$ Even when AgNWs were injected directly into the pleural space, it has been reported that AgNWs with a length $>10 \mu \mathrm{m}$ may cause frustrated phagocytosis, while most of the shorter AgNWs $(<5 \mu \mathrm{m})$ were fully internalized by pleural macrophage cells, using backscatter electron microscopy. ${ }^{10}$ Interestingly, AgNWs with lengths of both 5 and $10 \mu \mathrm{m}$ led to an aggregation of inflammatory cells on the surface of the parietal pleura with accumulation of AgNWs within the lesion area, whereas these effects were not seen only for very short $(3 \mu \mathrm{m})$ AgNWs.

Although Silva and colleagues ${ }^{12}$ intratracheally instilled different doses of AgNWs of longer length than us (2 and $20 \mu \mathrm{m}$ ), there were similarities in terms of the inflammatory response reported. With the $0.3 \mathrm{mg}$ dose of 1 and $10 \mu \mathrm{m}$ length compared to their 0.1 and $0.5 \mathrm{mg}$ doses of the longer AgNWs, the degree of inflammation was similar. In the histological quantitation of the lung inflammation, both studies reported a greater persistence of the inflammation up to day 21 with the S-AgNWs, while there was an early transient lung inflammatory response with the L-AgNWs. However, the one main important difference was that we did not observe the process of frustrated phagocytosis, as reported with the intratracheal instillation of $20 \mu \mathrm{m}$ length AgNWs by Silva et al. ${ }^{12}$ or with the intrapleural instillation of $>10 \mu \mathrm{m} \mathrm{AgNWs} .^{10}$ The process of frustrated phagocytosis has been reported with asbestos fibers which are less soluble than AgNWs. ${ }^{25}$ In addition, the length of our nanowires were limited to a maximal length of $10 \mu \mathrm{m}$ which can be internalized 
by single macrophages. More importantly, AgNWs underwent a significant reduction in length in vivo. Another important difference is that we instilled a lower amount of AgNWs by weight, using $0.3 \mathrm{mg} / \mathrm{kg}$ body weight compared to the amounts of 0.5 and $1.0 \mathrm{mg} / \mathrm{kg}$ used by Silva and colleagues. Therefore, taken together with the study of Silva et al., ${ }^{12}$ one might hypothesize that the threshold length of AgNWs for frustrated phagocytosis may be in the region of $10-20 \mu \mathrm{m}$ with a threshold weight of around $0.3-0.5 \mathrm{mg} / \mathrm{kg}$. However, these would need to be confirmed in further studies.

\section{CONCLUSION}

We have shown that AgNWs of 1 and $10 \mu \mathrm{m}$ in length are transformed into shorter lengths and fully internalized by lung cells such as macrophages and type II alveolar cells, a process that occurs within 1 day of intratracheal instillation in rats. This underlies the acute and transient inflammatory, cytokine, and bronchial hyperresponsiveness in the lungs particularly seen with the long AgNWs, which caused a greater and longer-lasting degree of lung inflammation with a more diverse cytokine production and crucially induced bronchial hyperresponsiveness. This effect of long AgNWs compared to the short AgNWs is likely due to the greater number and persistence of macrophages containing silver in the pleura and lung subpleural spaces. Overall, inactivation of $\mathrm{Ag}$ ions occurs after precipitation of $\mathrm{Ag}_{2} \mathrm{~S}$ intracellularly. Our results provide information regarding the risks of silver-based technologies, particularly in the area of nanowires to human health and to the potential for developing hyperresponsive airways disease that could include asthma.

\section{METHODS/EXPERIMENTAL SECTION}

Nanomaterials. AgNWs were prepared via a modified polyol pathway, through the reduction of $\mathrm{AgNO}_{3}$ by ethylene glycol (EG, Sigma-Aldrich, U.K.) in the presence of PVP $\left(M_{\mathrm{W}} \approx 360 \mathrm{~K}\right.$, SigmaAldrich, U.K.), as described by Chen et al. ${ }^{15}$ The length of the AgNWs was modified by altering the molar ratio of $\mathrm{PVP}$ to $\mathrm{AgNO}_{3}$ from 1.5 to 3.0. AgNWs were washed by repeated cycles of centrifugation $(5000 \mathrm{~g})$ with acetone, ethanol, and 3 times with deionized (DI) water, dispersed in DI water in a sealed glass vial, and stored at $4{ }^{\circ} \mathrm{C}$ in the dark. AgNWs were characterized by bright-field transmission electron microscopy (BF-TEM) using a JEOL JEM-2100F, combined with SAED and EDX (Oxford Instruments). The primary size distributions of AgNWs were characterized using several TEM images and ImageJ software (http:// rsb.info.nih.gov/ij/). The hydrodynamic diameter of AgNWs in water was measured using DLS (Malvern Zetasizer Nano series).

To measure $\mathrm{Ag}^{+}$ion release from $\mathrm{AgNWs}$, the suspensions were incubated at a concentration of $25 \mu \mathrm{g} / \mathrm{mL}$ from the original stock solutions in a temperature-controlled dri-block incubator at physiological temperature $\left(37^{\circ} \mathrm{C}\right)$ in $0.1 \mathrm{M}$ sodium perchlorate $\left(\mathrm{NaClO}_{4} \cdot \mathrm{H}_{2} \mathrm{O}\right.$, SigmaAldrich), with $\mathrm{pH} 7$ or 5, to simulate the characteristic environment in the lung. ${ }^{12}$ The amount of $\mathrm{Ag}^{+}$ions released was measured, following centrifugal filtration, ${ }^{12}$ by inductively coupled plasma-optical emission spectroscopy (ICP-OES, Thermo Scientific, U.K.) with a silver detection limit of $0.6 \mu \mathrm{g} / \mathrm{L}$. Solubility was expressed as the mass percentage of total $\mathrm{Ag}$ released as $\mathrm{Ag}^{+}$ions.

Intratracheal Instillation in Rats. All in vivo experiments were conducted under a home office license provided by the U.K. government. Sprague-Dawley rats, 8-10 weeks old (250-300 g), were purchased from Charles River (U.K.) and maintained under a $12 \mathrm{~h}$ light and dark cycle, with food and water provided ad libitum. AgNW (S-AgNW and L-AgNW) suspensions were water-bath sonicated for $1 \mathrm{~min}$, prior to dilution in DI water. As we have previously confirmed, the concentration of free $\mathrm{Ag}^{+}$ions in the $\mathrm{AgNW}$ stock solutions was below the ICP-OES detection limit. ${ }^{14}$ Intratracheal instillation of AgNW suspensions ( $0.3 \mathrm{~mL} ; 0.3 \mathrm{mg} / \mathrm{kg}, 100 \mu \mathrm{g} / \mathrm{rat}$ ) or the control (distilled water) was performed under isofluorane anesthesia (3 $\mathrm{min} / 3 \%$ isofluorane/3.5\% $\mathrm{O}_{2}$ ) using a ball-tipped needle maneuvered through the epiglottis, with confirmation by external palpation of contact with tracheal rings and by inflation of lungs with air. A $0.5 \mathrm{mg} / \mathrm{kg}$ dose of $\mathrm{AgNW}$ s has been shown to cause a degree of lung inflammation, ${ }^{12}$ and in order to induce just a minimal degree of lung inflammation, we chose a dose of $0.3 \mathrm{mg} / \mathrm{kg}$ to instil. $\mathrm{AgNO}_{3}$, used as another control, was instilled at $0.003 \mathrm{mg} / \mathrm{kg}$ to model the average concentration of silver ions (1\%) released from AgNWs in $\mathrm{pH} 7$ and 5 perchlorate buffers in $24 \mathrm{~h}$ (Table 1). ${ }^{14}$ After instillation, rats were returned to their cages and examined at 1,7 , or 21 days.

Bronchoalveolar Lavage (BAL). After lung function measurements, BAL was performed after an overdose of sodium pentobarbital, and cell differential cell count was obtained on BAL cell cytopin preparations as previously described. ${ }^{9}$ Total protein levels were measured using the Bradford protein assay (Biorad Laboratories, Hemel Hempsted, U.K.). BAL chemokines and cytokines were measured using the Milliplex MAP rat cytokine/chemokine panel (MerckMillipore) and detected using a Luminex 200 system (Luminex, Austin, TX). MDA was measured by an HPLC method with fluorescence detection (Waters, Milford, MA, U.S.A.) as previously described. ${ }^{9}$

Phospholipid and Surfactant Proteins. BALF contains pulmonary surfactant (PS) which can be separated by differential centrifugation into large aggregate (LA) and small aggregate (SA) fractions. The LA fraction contains SP-A, SP-B, and SP-C, phospholipids, tubular myelin, lamellar bodies, and large vesicles and has superior surface active properties compared with the SA fraction. ${ }^{27}$ Phospholipid was measured in the LA fractions by the method of Bartlett. ${ }^{28}$ Briefly, $1 \mathrm{~mL}$ of BAL supernatant was centrifuged at $18,000 \mathrm{~g}$ at $4{ }^{\circ} \mathrm{C}$, and the LA fraction (pellet) was suspended in $40 \mu \mathrm{L}$ of saline. Total lipids were extracted from $5 \mu \mathrm{L}$ of the LA fraction using a Bligh and Dyer extraction following a perchloric acid digestion for $1 \mathrm{~h}$ at $200^{\circ} \mathrm{C}$. Levels of organic phosphate were measured against a potassium phosphate standard curve. SP-D was measured in undiluted whole BAL supernatant using a rat specific ELISA kit following the manufacturer's protocol (Cusabio Biotech, Newmarket, Suffolk, U.K.).

Lung Mechanics. Rats were anaesthetised using hypnorm/hypovel intraperitoneally $(2.7 \mathrm{mg} / \mathrm{kg})$, tracheotomized and ventilated using a computer controlled ventilator (eSpira, EMMS) at a tidal volume of $10 \mathrm{~mL} / \mathrm{kg}$ and a frequency of 90 breaths per minute. Positive end expiratory pressure (PEEP) was maintained at $5 \mathrm{~cm} \mathrm{H}_{2} \mathrm{O}$, and volume history was regulated by three successive inflations to total lung capacity $(30 \mathrm{~cm}$ $\mathrm{H}_{2} \mathrm{O}$ ), prior to taking measurements. Pulmonary function was measured using the forced oscillation technique. Respiratory impedance was measured following interruption of normal breathing by an $8 \mathrm{~s}$ sinusoidal oscillation containing multiple frequencies ranging between 0.5 and $20 \mathrm{~Hz}$. Respiratory impedance data were fitted to the constant phase model, which partitions impedance signals into those originating in the large airway ( $\mathrm{Rn}$, large airway resistance) and the small airways and tissues ( $G$, tissue resistance and $H$, tissue elastance). ${ }^{29}$ Similar changes in $G$ and $H$ reflect collapse of the small airways, while dissimilar changes describe heterogeneity in airway ventilation. ${ }^{30}$ Measurements were recorded at baseline and also following nebulization of $20 \mu \mathrm{L}$ of increasing concentrations of acetylcholine $(0,2,4,8,16,32$, and $64 \mathrm{mg} / \mathrm{mL}$ ).

Lung Inflammation and Silver-Stained Lung Cells. The left lung was embedded into paraffin, and $5 \mu \mathrm{m}$ sections were stained with hematoxylin and eosin (BDH Lutterworth, U.K.). The inflammation was scored on a $0-3$ scale as previously described. ${ }^{9}$ Deposition of silver in lung tissue sections was performed by autometallography using a silver enhancing Kit (cat no: SE100, Sigma-Aldrich, Saint Louis, U.S.A.) as previously described, with the use of silver-enhancing solutions and fixation with sodium thiosulfate, followed by nuclear fast red counterstain. ${ }^{9}$ AgNWs were visualized under light microscopy. $\mathrm{The}^{+} \mathrm{Ag}^{+}$cells were counted on 20 fields across the whole section of left lung, excluding the subpleural areas. The $\mathrm{Ag}^{+}$cells deposited in pleural region including the subpleural alveoli were counted in 20-half-fields along the $200 \mu \mathrm{m}$ distance from the pleura of the left lung.

TEM and 3D SEM Imaging of Silver Nanowires in Lung and BAL Cells. Rats were exposed by intratracheal instillation to $0.5 \mathrm{mg} / \mathrm{kg}$ of AgNWs in a $0.5 \mathrm{~mL}$ volume as previously described. Rats were 
returned to their cages for either 2 or $24 \mathrm{~h}$. Rats were sacrificed by an overdose of sodium pentobarbital, and the lungs were immediately perfused with $2 \times 60 \mathrm{~mL}$ of saline via the vasculature, followed by perfusion with fixative (2\% formaldehyde/ $2 \%$ glutaraldehyde in $0.1 \mathrm{M}$ PIPES buffer, containing $2 \mathrm{mmol} / \mathrm{L}$ calcium chloride). Lungs were removed and fixed overnight, before rinsing with and then storing in normal saline. BAL cells were rinsed in physiological saline, and cells were fixed for $1 \mathrm{~h}$ at $4{ }^{\circ} \mathrm{C}$ in $2.5 \%$ glutaraldehyde in $0.1 \mathrm{M}$ Pipes buffer, $\mathrm{pH}$ 7.2. After fixation, cells and tissues were washed 5 times in saline and dehydrated in an ascending series of ethanol solutions to $100 \%$ dry ethanol. They were stained in $4 \%$ magnesium uranyl acetate in $100 \%$ ethanol for $48 \mathrm{~h}$, rinsed 4 times in 100\% dry ethanol, and infiltrated with Quetol 651 epoxy resin over 4 days. Quetol was cured at $65^{\circ} \mathrm{C}$ for a minimum of $48 \mathrm{~h} .{ }^{13}$ In previous work, we have shown that this preparation procedure for electron microscopy does not alter the physicochemistry of the AgNWs. ${ }^{21}$ For TEM and serial block face SEM, small pieces of tissues embedded in Quetol were glued to aluminum pins with CW2400 conductive epoxy resin (ITW Chemtronics). They were sputter coated with $100 \mathrm{~nm}$ of gold in a Quorum K575X and transferred to a Leica ultracut UCT where a flat surface was generated using a $35^{\circ}$ wedge angle Diatome diamond knife. The block face was $1.5 \times 1.5 \mu \mathrm{m}$. Subsequent to thin sectioning, the blocks were retrieved and coated with carbon and preselected for serial block face imaging in a FEI Verios 460 operated at $3 \mathrm{keV}$ and 50pA using a concentric backscatter detector. For electron microscopy imaging and analysis, the lungs of two rats were studied for both the S- and L-AgNWs. For each animal, three lobes of each lung were analyzed.

For TEM analysis, sections of fixed and embedded cells were cut with an ultramicrotome using a $35^{\circ}$ wedge angle diamond knife and floated on distilled water. Sections were immediately collected on uncoated 300 mesh copper grids (Agar Scientific, Stansted, U.K.) and dried for $30 \mathrm{~min}$ at $37^{\circ} \mathrm{C}$. Sections of $70-100 \mathrm{~nm}$ thickness were used for imaging studies. The block face was used for serial 3D imaging.

3D SEM Images of Silver Nanowires in Lung and BAL Cells. For serial block face SEM, serial sections were generated in a FEI Quanta 250 FEG-environmental (E-)SEM using an in situ ultramicrotome (Gatan, 3View). The individual images were acquired at an electron beam voltage of $3.5 \mathrm{keV}$ using a backscattered electron detector in lowvacuum mode at $90 \mathrm{~Pa}$. The nominal thickness of the individual slices was $40 \mathrm{~nm}$, and the image sizes were $40 \times 40 \mu \mathrm{m}$. The $3 \mathrm{D}$ reconstruction was generated from 300 slices and pixel size of $19.2 \times 19.2 \mathrm{~nm}$. The 3D reconstruction was performed using Gatan Digital Micrograph software and also Bitplane Imaris 3D reconstruction software.

Acquisition of TEM Images of Silver Nanowires in Lung and BAL Cells. Bright-field TEM imaging was performed on a JEOL 2000 microscope operated at $80 \mathrm{kV}$ and an FEI Titan 80-300 scanning/ transmission electron microscope (S/TEM) operated at $80 \mathrm{kV}$, fitted with Cs (image) corrector and SiLi EDX spectrometer (EDAX, Leicester U.K.). High-angle annular dark-field scanning transmission electron microscopy (HAADF-STEM) experiments were performed with a convergence semiangle of $14 \mathrm{mrad}$ and inner and outer HAADF collection angles of 49 and $239 \mathrm{mrad}$, respectively. The probe diameter was $<0.5 \mathrm{~nm}$. The intensity of the signal, using the HAADF detector is proportional $\mathrm{Z}^{2}$ of the material being analyzed, therefore this detector was used to enhance contrast from the AgNWs and heavy metal-stained cell organelles.

Processing and Quantification of 3D SEM Data Sets. Data sets acquired by serial block face SEM imaging were visualized in AvizoLite (v9.0.1, FEI, U.S.A.), and cells containing nanowires were segmented by intensity-based thresholding. A smoothing algorithm (3D mean) was applied using ImageJ (v1.48) prior to a semiautomated procedure used to segment individual AgNWs. The identification of separate nanowires was then carried out using a binary watershed applied using QuiQ 3D (IQM Elements, London, U.K.), followed by manual inspection and final adjustment of the segmentation results using Avizo (9.01, FEI, U.S.A.). Advanced quantification was performed using QuiQ 3D. The feret diameters were determined through a hypersphere to fit the nanowires and calculate nanowire length. ${ }^{20}$ Incompletely described particles or nanowires (i.e., those that extend out of the field of view captured using 3D SEM) were removed leaving a total of 116 completely described nanowires, contained within two cells, to be quantified.

Statistical Analysis. Data were assessed for normality using the Shapiro-Wilk test. Comparison of the means of nonparametric data at the three time points was performed by an ANOVA (Kruskal-Wallis test) with the differences between individual groups assessed by the Dunns posthoc test. Due to the non-normal distributions of AgNW lengths, the two-sample Kolmogorov-Smirnov test was used to compare the similarity of AgNWs lengths before and after internalization in epithelial cells. Differences in lung function for AgNW treatments compared with the distilled water control were assessed using a two-way ANOVA with a Bonferroni posthoc test to assess differences between individual concentrations. A $p$ value of $<5 \%$ was taken as significant.

\section{ASSOCIATED CONTENT}

\section{S Supporting Information}

The Supporting Information is available free of charge on the ACS Publications website at DOI: 10.1021/acsnano.6b07313.

Supplementary Figures 1 and 2 (PDF)

Serial block face stack of lung tissue with AgNWcontaining cells. The video shows a serial block face data set taken over a volume of $40 \times 40 \times 11 \mu \mathrm{m}$ of lung tissue $(20 \times 20 \times 40 \mathrm{~nm}$ voxel size $)$. Within this volume, two type II epithelial cells are observed to contain Ag-NWs. These two cells were segmented to visualize the distribution of Ag-NWs within the cells; the surfaces displayed are plasma membranes (light blue), cell nuclei (dark blue), and NWs (orange) (AVI)

\section{AUTHOR INFORMATION}

\section{Corresponding Author}

*E-mail: f.chung@imperial.ac.uk.

ORCID

Kian Fan Chung: 0000-0001-7101-1426

Ioannis G. Theodorou: 0000-0002-9572-417X

Christos Rossios: 0000-0003-3470-3233

Notes

The authors declare no competing financial interest.

\section{ACKNOWLEDGMENTS}

K.F.C., J.Z., T.D.T., M.P.R., and A.E.P. acknowledge funding from the U.S. National Institute for Environmental Health Sciences grant no. U19ES019536 and from the U.K. National Environmental Research Council grant NE/H012893. A.E.P. acknowledges a European Research Council starting grant no. 257182 (CNTBBB) and an Elsie Widdowson Research Fellowship.

\section{REFERENCES}

(1) Liu, C. H.; Yu, X. Silver Nanowire-Based Transparent, Flexible, and Conductive Thin Film. Nanoscale Res. Lett. 2011, 6, 75.

(2) De, S.; Higgins, T. M.; Lyons, P. E.; Doherty, E. M.; Nirmalraj, P. N.; Blau, W. J.; Boland, J. J.; Coleman, J. N. Silver Nanowire Networks as Flexible, Transparent, Conducting Films: Extremely High DC to Optical Conductivity Ratios. ACS Nano 2009, 3, 1767-74.

(3) Lu, Y. C.; Chou, K. S. Tailoring of Silver Wires and their Performance as Transparent Conductive Coatings. Nanotechnology 2010, 21, 215707.

(4) Weldon, B. A.; Faustman, E. M.; Oberdorster, G.; Workman, T.; Griffith, W. C.; Kneuer, C.; Yu, I. J. Occupational Exposure Limit for Silver Nanoparticles: Considerations on the Derivation of a General Health-based Value. Nanotoxicology 2016, 10, 945-956. 
(5) Park, M. V.; Neigh, A. M.; Vermeulen, J. P.; de la Fonteyne, L. J.; Verharen, H. W.; Briede, J. J.; van Loveren, H.; de Jong, W. H. The Effect of Particle Size on the Cytotoxicity, Inflammation, Developmental Toxicity and Genotoxicity of Silver Nanoparticles. Biomaterials 2011, 32, 9810-9817.

(6) Braakhuis, H. M.; Gosens, I.; Krystek, P.; Boere, J. A.; Cassee, F. R.; Fokkens, P. H.; Post, J. A.; van Loveren, H.; Park, M. V. Particle Size Dependent Deposition and Pulmonary Inflammation after Short-Term Inhalation of Silver Nanoparticles. Part. Fibre Toxicol. 2014, 11, 49.

(7) Sung, J. H.; Ji, J. H.; Yoon, J. U.; Kim, D. S.; Song, M. Y.; Jeong, J.; Han, B. S.; Han, J. H.; Chung, Y. H.; Kim, J.; et al. Lung function Changes in Sprague-Dawley Rats after Prolonged Inhalation Exposure to Silver Nanoparticles. Inhalation Toxicol. 2008, 20, 567-574.

(8) Song, K. S.; Sung, J. H.; Ji, J. H.; Lee, J. H.; Lee, J. S.; Ryu, H. R.; Lee, J. K.; Chung, Y. H.; Park, H. M.; Shin, B. S.; et al. Recovery from Silvernanoparticle-exposure-induced Lung Inflammation and Lung Function Changes in Sprague Dawley rats. Nanotoxicology 2013, 7, 169-180.

(9) Seiffert, J.; Hussain, F.; Wiegman, C.; Li, F.; Bey, L.; Baker, W.; Porter, A.; Ryan, M. P.; Chang, Y.; Gow, A.; Zhang, J.; et al. Pulmonary Toxicity of Instilled Silver Nanoparticles: Influence of Size, Coating and Rat Strain. PLoS One 2015, 10, e0119726.

(10) Schinwald, A.; Donaldson, K. Use of Back-scatter Electron Signals to Visualise Cell/Nanowires Interactions in vitro and in vivo; Frustrated Phagocytosis of Long Fibres in Macrophages and Compartmentalisation in Mesothelial Cells in vivo. Part. Fibre Toxicol. 2012, 9, 34.

(11) Schinwald, A.; Murphy, F. A.; Prina-Mello, A.; Poland, C. A.; Byrne, F.; Movia, D.; Glass, J. R.; Dickerson, J. C.; Schultz, D. A.; Jeffree, C. E.; et al. The Threshold Length for Fber-induced Acute Pleural Inflammation: Shedding Light on the Early Events in Asbestos-induced Mesothelioma. Toxicol. Sci. 2012, 128, 461-470.

(12) Silva, R. M.; Xu, J.; Saiki, C.; Anderson, D. S.; Franzi, L. M.; Vulpe, C. D.; Gilbert, B.; Van Winkle, L. S.; Pinkerton, K. E. Short versus Long Silver Nanowires: a Comparison of in vivo Pulmonary Effects Postinstillation. Part. Fibre Toxicol. 2014, 11, 52.

(13) Sweeney, S.; Theodorou, I. G.; Zambianchi, M.; Chen, S.; Gow, A.; Schwander, S.; Zhang, J. J.; Chung, K. F.; Shaffer, M. S.; Ryan, M. P.; et al. Silver Nanowire Interactions with Primary Human Alveolar type-II Epithelial Cell Secretions: Contrasting Bioreactivity with Human Alveolar type-I and type-II Epithelial Cells. Nanoscale 2015, 7, 10398-10409.

(14) Theodorou, I. G.; Botelho, D.; Schwander, S.; Zhang, J.; Chung, K. F.; Tetley, T. D.; Shaffer, M. S.; Gow, A.; Ryan, M. P.; Porter, A. E. Static and Dynamic Microscopy of the Chemical Stability and Aggregation State of Silver Nanowires in Components of Murine Pulmonary Surfactant. Environ. Sci. Technol. 2015, 49, 8048-8056.

(15) Chen, S.; Theodorou, I. G.; Goode, A. E.; Gow, A.; Schwander, S.; Zhang, J. J.; Chung, K. F.; Tetley, T. D.; Shaffer, M. S.; Ryan, M. P.; et al. High-resolution Analytical Electron Microscopy Reveals Cell Culture Media-Induced Changes to the Chemistry of Silver Nanowires. Environ. Sci. Technol. 2013, 47, 13813-13821.

(16) Miclaus, T.; Beer, C.; Chevallier, J.; Scavenius, C.; Bochenkov, V. E.; Enghild, J.J.; Sutherland, D. S. Dynamic Protein Coronas Revealed as a Modulator of Silver Nanoparticle Sulphidation in vitro. Nat. Commun. 2016, 7, 11770.

(17) Leo, B. F.; Chen, S.; Kyo, Y.; Herpoldt, K. L.; Terrill, N. J.; Dunlop, I. E.; McPhail, D. S.; Shaffer, M. S.; Schwander, S.; Gow, A.; et al. The Stability of Silver Nanoparticles in a Model of Pulmonary Surfactant. Environ. Sci. Technol. 2013, 47, 11232-11240.

(18) Chen, S.; Goode, A. E.; Sweeney, S.; Theodorou, I. G.; Thorley, A. J.; Ruenraroengsak, P.; Chang, Y.; Gow, A.; Schwander, S.; Skepper, J.; et al. Sulfidation of Silver Nanowires inside Human Alveolar Epithelial Cells: a Potential Detoxification Mechanism. Nanoscale 2013, 5, 98399847.

(19) Gracie, J. A.; Robertson, S. E.; McInnes, I. B. Interleukin-18. J. Leukocyte Biol. 2003, 73, 213-224.

(20) Leung, B. P.; Culshaw, S.; Gracie, J. A.; Hunter, D.; Canetti, C. A.; Campbell, C.; Cunha, F.; Liew, F. Y.; McInnes, I. B. A Role for IL-18 in Neutrophil Activation. J. Immunol. 2001, 167, 2879-2886.
(21) Wang, L.; Zhang, T.; Li, P.; Huang, W.; Tang, J.; Wang, P.; Liu, J.; Yuan, Q.; Bai, R.; Li, B.; et al. Use of Synchrotron Radiation-Analytical Techniques To Reveal Chemical Origin of Silver-Nanoparticle Cytotoxicity. ACS Nano 2015, 9, 6532-6547.

(22) Veronesi, G.; Aude-Garcia, C.; Kieffer, I.; Gallon, T.; Delangle, P.; Herlin-Boime, N.; Rabilloud, T.; Carriere, M. Exposure-dependent Ag+ Release from Silver Nanoparticles and its Complexation in AgS2 Sites in Primary Murine Macrophages. Nanoscale 2015, 7, 7323-7330.

(23) Mu, Q.; Jiang, G.; Chen, L.; Zhou, H.; Fourches, D.; Tropsha, A.; Yan, B. Chemical Basis of Interactions Between Engineered Nanoparticles and Biological Systems. Chem. Rev. 2014, 114, 7740-7781.

(24) Ruge, C. A.; Schaefer, U. F.; Herrmann, J.; Kirch, J.; Canadas, O.; Echaide, M.; Perez-Gil, J.; Casals, C.; Muller, R.; Lehr, C. M. The Interplay of Lung Surfactant Proteins and Lipids Assimilates the Macrophage Clearance of Nanoparticles. PLoS One 2012, 7, e40775.

(25) Donaldson, K.; Murphy, F. A.; Duffin, R.; Poland, C. A. Asbestos, Carbon Nanotubes and the Pleural Mesothelium: a Review of the Hypothesis Regarding the Role of Long Fibre Retention in the Parietal Pleura, Inflammation and Mesothelioma. Part. Fibre Toxicol. 2010, 7, 5.

(26) Ryman-Rasmussen, J. P.; Cesta, M. F.; Brody, A. R.; ShipleyPhillips, J. K.; Everitt, J. I.; Tewksbury, E. W.; Moss, O. R.; Wong, B. A.; Dodd, D. E.; Andersen, M. E.; et al. Inhaled Carbon Nanotubes Reach the Subpleural Tissue in Mice. Nat. Nanotechnol. 2009, 4, 747-751.

(27) Veldhuizen, R. A.; Inchley, K.; Hearn, S. A.; Lewis, J. F.; Possmayer, F. Degradation of Surfactant-Associated Protein B (SP-B) During in vitro Conversion of Large to Small Surfactant Aggregates. Biochem. J. 1993, 295, 141-147.

(28) Bartlett, D.; Glaser, M.; Welti, R. Membrane Penetration Depth and Lipid Phase Preference of Acyl-labeled Dansyl Phosphatidylcholines in Phosphatidylcholine Vesicles. Biochim. Biophys. Acta, Biomembr. 1997, 1328, 48-54.

(29) Hantos, Z.; Adamicza, A.; Govaerts, E.; Daroczy, B. Mechanical Impedances of Lungs and Chest Wall in the Cat. J. Appl. Physiol. 1992, $73,427-433$

(30) Bates, J. H. Pulmonary Mechanics: a System Identification Perspective. Conf Proc. IEEE Eng. Med. Biol. Soc. Annual Conference 2009, 2009, 170-172. 